\title{
Net Income Measurement, Investor Inattention, and Firm Decisions
}

\section{Natee Amornsiripanitch}

Federal Reserve Bank of Philadelphia Supervision, Regulation, and Credit Department

\section{Zeqiong Huang}

Yale School of Management

WP22-05

PUBLISHED

February 2022

\section{David Kwon}

Yale School of Management

Jinjie Lin

Yale School of Management

ISSN: 1962-5361

Disclaimer: This Philadelphia Fed working paper represents preliminary research that is being circulated for discussion purposes. The views expressed in these papers are solely those of the authors and do not necessarily reflect the views of the Federal Reserve Bank of Philadelphia or the Federal Reserve System. Any errors or omissions are the responsibility of the authors. 


\title{
Net Income Measurement, Investor Inattention, and Firm Decisions*
}

\author{
Natee Amornsiripanitch \\ Federal Reserve Bank of Philadelphia ${ }^{\dagger}$ \\ natee.amornsiripanitch@phil.frb.org
}

\author{
David Kwon \\ Yale School of Management \\ david.kwon@yale.edu
}

\author{
Zeqiong Huang \\ Yale School of Management \\ zeqiong.huang@yale.edu
}

\author{
Jinjie Lin \\ Yale School of Management \\ jinjie.lin@yale.edu
}

\begin{abstract}
When investors have limited attention, does the way in which net income is measured matter for firm value and firms' resource allocation decisions? This paper us es the Accounting Standards Update (ASU) 2016-01, which requires public firms to incorporate changes in unrealized gains and losses (UGL) on equity securities into net income, to answer this question. We build a model with risk-averse investors who can be attentive or inattentive and managers who choose how much to invest in financial assets to maximize firms' stock prices. The model predicts that, with inattentive investors, stock prices react more to changes in UGL from equity securities under the new regime and, under certain conditions, investors assign larger price discounts. Managers respond to such discounts by cutting financial asset holdings. We use insurance company data to test these predictions. Prices of stocks with low analyst coverage react more to changes in UGL from equity securities, highlighting the role of investor inattention. Using a difference-indifferences approach, we find that by 2020, publicly traded insurance companies cut investments in public stocks by $\$ 23$ billion.
\end{abstract}

JEL Codes: G11, G14, G22, G30, M41

Keywords: Net income components, investor inattention, ASU 2016-01, capital allocation decisions

\footnotetext{
${ }^{*}$ The first draft of this paper was circulated on November 13, 2021. We thank the Yale School of Management for financial support. We thank Frank Zhang for insightful comments. We thank participants of the Yale SOM Accounting Lunch Seminar for their questions and comments. We also thank individuals at BlackRock, Vanguard, RBC Capital, Credit Suisse, and PricewaterhouseCoopers for helpful discussions. The contents of this paper do not necessarily reflect the views of the Federal Reserve Bank of Philadelphia or the Federal Reserve System. Philadelphia Fed working papers are free to download at https://philadelphiafed.org/research-and-data/publications/working-papers. All data used in this work are licensed through Yale University. The contents of this paper are not investment or legal advice.

${ }^{\dagger}$ Natee Amornsiripanitch was formerly a graduate student at Yale School of Management. This paper was authored prior to his current position at the Federal Reserve Bank of Philadelphia.
} 


\section{Introduction}

Does the way in which accounting information is presented to investors matter for real economic decisions? A recurring form of this debate is whether an item should be recognized as part of net income, recognized as part of other comprehensive income, or merely disclosed in the footnote. Firms spend vast resources on lobbying to influence a ccounting s tandard s ettings, w hich suggests that market participants care about how net income should be calculated. On the other hand, the efficient markets view of finance and accounting posits that the way in which accounting information is presented should not have real economic effects, as long as all necessary pieces of information are disclosed (Schipper, 2007).

This paper bridges the gap between these opposing views by showing that the way in which accounting information is presented to investors has real economic consequences when investors are inattentive. Limited attention can arise when investors face constraints, due to lack of cognitive abilities or other resources, when acquiring and processing information necessary for trading decisions (Blankespoor, deHaan, and Marinovic, 2020). When attention is constrained, summary accounting measures such as net income become useful because, although imperfect, they can provide informative signals about firm value in a concise manner. Therefore, the way in which these measures are constructed can have real economic consequences.

To demonstrate this point, we exploit the Financial Accounting Standards Board's (FASB) Accounting Standards Update (ASU) 2016-01, which requires public firms to incorporate changes in unrealized gains and losses (UGL) - the changes in fair value - on equity securities into net income. This natural experiment provides a unique opportunity to study the interaction between net income construction and investor inattention because the rule change only changes the way in which information regarding UGL on equity securities is presented on financial statements, while holding fixed the quantity and quality of such information 11 This feature of the rule allows us to conduct a clean empirical study of whether changes in the components of net income have detectable effects on firm values and firms' decisions.

While the net income measure under ASU 2016-01 could be considered a more complete measure

\footnotetext{
${ }^{1}$ Prior to ASU 2016-01, for equity securities that were classified as available-for-sale, UGL were reported as part of other comprehensive income. For equity securities that were classified as trading securities, UGL were reported as part of net income.
} 
of changes in shareholders' wealth in that period if we assume that firms immediately liquidate their equity securities investments, it mixes the firm's core operating earnings with changes in the value of marketable securities, which have different implications for the firm's total value. If investors are fully rational and perfectly attentive, then this rule change should not have any observable effect on their economic decisions. However, if investors are inattentive and only focus on summary measures, then they may treat these fluctuations in net income as meaningful changes in the companies' prospects and trade accordingly. Since the manager's compensation is often tied to the company's stock price, inattentive investors' irrational behaviors may affect firms' decision to invest in public stocks.

The issue of whether to include changes in UGL on equity securities into net income is also a hotly debated topic among market participants. As public companies hold more marketable securities (Darmouni and Mota, 2020), fluctuations in unrealized gains and losses on these assets during a given reporting period can become large relative to net income. Therefore, including such changes in values into net income may impair the accounting measure's ability to serve as a good indicator of the firm's c ore business performance, especially during periods of high stock market volatility. For example, Warren Buffett, a renowned investor, criticized the rule change by saying that it would "severely distort" his firm's net income number and render it "useless" for analytical purposes (Buffett, 2018). On the other hand, FASB argues that the new net income number is a more accurate measure of shareholders' wealth because UGL on equity securities can be realized via liquidation (Financial Accounting Standards Board, 2016). Our paper informs this debate by showing that, due to investor inattention, incorporating changes in UGL on equity securities into net income distorts firm values and firms' investment al location decisions.

We begin our analysis by constructing a model with risk-averse investors, who can be attentive or inattentive, and a manager who chooses the optimal level of financial assets to maximize firms' stock price. In our model, the firm has two streams of earnings: operating income and financial income. Operating income is from the firm's core business and financial income comes from changes in unrealized gains and losses from its marketable securities investments. Operating income contains some measurement error but is more persistent. On the other hand, changes in UGL on marketable securities can be accurately measured, but such changes in UGL can be volatile and unpredictable. Attentive investors can process and understand the two streams of earnings and how they impact 
firm value. On the other hand, inattentive investors cannot tell these two earnings components apart and, instead, value the firm based on the net income measure alone. Hence, the way in which net income is computed matters for investors' decisions.

In equilibrium, the firm's stock price is jointly determined by inattentive and attentive investors. The model's key results are borne out by comparing equilibrium outcomes between two accounting regimes - exclusive (inclusive) regime which excludes (includes) changes in UGL on equity securities from (into) net income. The exclusive regime represents the pre-ASU 2016-01 era where net income excludes financial income, which represents changes in equity UGL. The inclusive regime represents the post-ASU 2016-01 era where net income includes financial income. Since financial income is more volatile and less persistent, net income numbers mechanically become more volatile and less persistent under the inclusive regime. Investors learn about firm values by observing variations in net income and trade accordingly, which means that the composition of net income affects stock prices. The first key result from the model is that, under the inclusive regime, firms' stock prices react more strongly to financial income. $T$ his result is d riven by inattentive investors' inability to distinguish between operating and financial income streams.

We next identify the conditions under which firms' stock prices experience larger discounts under the inclusive regime (compared to the exclusive regime). We find that the price discount is larger when financial income has low persistence and/or large amounts of noise. This is because risk-averse investors assign larger discounts when they face higher residual uncertainty, defined as the remaining uncertainty regarding firm value once valuation signals have been observed. Holding fixed the amount of financial assets that firms invest in, inattentive investors know nothing about financial income when it is excluded from net income. However, when net income mechanically combines operating and financial income, net income becomes less informative if the two streams of earnings are less correlated. Since residual uncertainty affects stock price discounts, the incorporation of financial income into net income can affect firms' decisions.

We also model managers' decisions on how much to invest in financial assets. We compare the optimal amount of funds firms allocate to financial assets under the two regimes. We find that firms invest less in financial assets when financial income is either (1) less persistent, or (2) measured more precisely. This is because when the financial income is less persistent, it is less correlated with operating income, making it harder to infer the firm's total value. This result is borne out by 
the interaction between the manager's incentive to maximize her firm's stock price and the price discount caused by inattentive investors. Due to fluctuations in financial asset values, net income numbers are more volatile than core earnings, under the inclusive regime, which induces larger price discounts in equilibrium. In response, managers reduce their firms' holdings of financial assets to attenuate the downward pressure on their firms' stock prices.

The second part of the paper uses hand-collected data on insurance companies' changes in unrealized gains and losses from equity investments to test our model's predictions. We choose to focus our empirical analysis on insurance companies because of two reasons. First, insurance companies make up a large class of institutional investors that allocate a non-trivial amount of capital to publicly traded stocks. Among US public firms that existed in 2017, insurance companies held $80 \%$ of equity securities impacted by the rule change, or approximately $\$ 235$ billion. Insurers were disproportionately impacted by the rule because the rule only changed the accounting for equity securities held for the long-term and insurers, due to the nature of their business, tend to be long-term investors ${ }^{2}$ This feature of the industry allows us to study the impact that ASU 2016-01 has on firms' investment allocation decisions. Second, all US-based insurance companies disclose detailed investment data to the National Association of Insurance Commissioners (NAIC), which allows us to study the differential impact that ASU 2016-01 has on publicly traded insurers, while using private insurance companies as the control group.

We begin our empirical analysis by documenting basic facts about public insurance companies' earnings before and after the implementation of ASU 2016-01. We show that, after ASU 2016-01 was implemented, earnings volatility increased and earnings persistence decreased. These findings are not surprising, given the volatility of stock prices. However, they provide evidence that changes in UGL on equity securities are a high-volatility and low-persistence component of net income, which are important assumptions that drive our model's results.

Next, we use the event study approach to test whether investors overreact to changes in net income that come from changes in equity UGL that are disclosed on earnings announcement dates. We compare the pre-ASU 2016-01 period return responses to changes in UGL on equity securities

\footnotetext{
${ }^{2}$ The percentage falls to $52 \%$ if we exclude Berkshire Hathaway. Though banks hold significant amounts of equities, they were largely not impacted by the rule change because they tended to classify these positions as trading securities before the rule change, which meant that changes in UGL were already included in net income. Banks tended to classify equity securities as trading because equity securities were often held as part of their brokerage business, market making, and proprietary trading.
} 
investments to their post-period counterparts. If information from changes in equity UGL was already incorporated into investors' trading decisions, then we should not observe any difference in stock return responses between the two time periods. We find that $\mathrm{r}$ isk-adjusted stock returns do not respond to changes in equity UGL in the pre-period, but do in the post-period, even after conditioning on core earnings surprises and other conventional control variables. The magnitudes of these return responses are economically large. A 1 percentage point increase in changes in UGL on equity securities investments induces a 70 to 120 basis points (bps) increase in risk-adjusted return. This result supports the story that inattentive investors only pay attention to changes in UGL on equity securities when they are included in net income.

These return reactions are persistent. When companies experience relatively positive changes in equity UGL, stock returns jump up and stay high for up to 40 trading days after the earnings announcement date. When companies experience relatively negative changes in equity UGL, stock returns drop and stay low for up to 60 trading days after the earnings announcement date. Most of the return reactions occur within 10 trading days of the earnings announcement date. Furthermore, this pattern does not show up in the pre-ASU 2016-01 period. These return reaction results are consistent with our model's first prediction and suggest that inattentive investors are driving these return patterns.

Our model predicts that inattention causes investors to underreact (overreact) to changes in equity UGL in the pre-period (post-period). To give credence to the proposed mechanism, we test for differences in stock return reactions between insurance companies that have many sellside equity analysts covering them and those that have few. Investors face information processing costs (Engelberg, 2008; Blankespoor et al., 2020) and sell-side equity analysts lower this cost by presenting synthesized versions of companies' financial statements that more cleanly capture the companies' current and future performances. With respect to ASU 2016-01, anecdotally, analysts generally exclude changes in equity UGL from their earnings forecasts, which allows investors to learn about the company's core performance more easily. Therefore, if inattentive investors read analyst reports, then they are less likely to overreact to changes in equity UGL. We find that this is indeed the case. Return reactions are relatively muted among companies that have relatively high analyst coverage.

To provide additional evidence that stock prices are reacting to the inclusion of changes in equity 
UGL into net income, we devise a trading strategy that exploits the delay between stock investment returns and the associated reported changes in equity UGL at earnings announcements. This trading strategy only involves stocks of insurance companies that have positive equity investment allocations. For a given quarter, if the Center for Research in Security Prices (CRSP) value-weighted index return is positive, then, during the following quarter, buy each insurance company's stock one day before each company's earnings announcement date and hold the stock for 10 trading days after the earnings announcement. If the CRSP value-weighted index return is negative, then, during the following quarter, sell short each insurance company's stock one day before each company's earnings announcement and unwind the position 10 trading days after the announcement date. Stocks are weighted according to the companies' equity allocation percentage such that the weights add up to one in each quarter. In the pre-period, this strategy does not generate significant profits. However, in the post-period, the weighted average return of this strategy is $2.5 \%$ and is statistically different from zero. Furthermore, the average equity-allocation-weighted return is larger than the average equal-weighted return, which provides more evidence that stock returns are indeed reacting to changes in equity UGL in the post-period.

The final key result from our model is that, when inattentive investors perceive post-ASU 2016-01 earnings to be more volatile and less informative about firm value, they assign larger discounts to companies' stock prices and managers respond by reducing capital allocated to equity securities. We use a difference-in-difference identification strategy to test whether ASU 2016-01 caused publicly traded insurance companies to decrease their equity securities allocation relative to their privately held counterparts. We find that, after ASU 2016-01 was implemented, insurance subsidiaries of publicly traded companies decreased their allocation to publicly traded stocks by 0.47 percentage points. A back-of-the-envelope calculation shows that, by 2020, insurance subsidiaries of publicly traded companies reduced their holdings of public stocks by approximately $\$ 23$ billion, which is equivalent to approximately half of their aggregate public stock holdings. Since public stocks tend to yield higher long-run returns than bonds, these results suggest that ASU 2016-01 may have decreased insurance companies' long-run portfolio returns and ability to meet insurance policy payouts. Taken together, the results from this paper show that the behavior of inattentive investors can affect managers' investment allocation decisions through the interaction between stock prices and managers' incentives. 
In an independent and contemporaneous work, Song, Wang, and Wheeler (2021) use ASU 201601 to show that property and casualty $(\mathrm{P} \& \mathrm{C})$ insurance companies respond to the rule change by tilting their investment portfolios away from volatile stocks in an attempt to lower net income volatility. The work by Song et al. (2021) complements the results presented in this paper well. However, it is important to note that this paper differs from Song et al. (2021) in several ways. First, we build a model that explicitly shows why the rule change should affect firms' investment allocation decisions. The mechanism that we propose is the interaction between investor inattention and managers' incentive to maximize their firms' stock prices. Second, we provide concrete empirical evidence in support of our model's predictions. Specifically, we show that stock prices react to changes in equity UGL and more so for companies that are more likely to have less attentive investors. We then show that affected companies tilt their investment portfolios away from stocks altogether. Lastly, we devise a profitable trading strategy that exploits changes in equity UGL, which suggests that ASU 2016-01 may have made the market for insurance companies' stocks less efficient.

Our paper contributes to several strands of accounting and finance literature. First, this paper contributes to the literature that focuses on the impact of investors' limited attention on asset prices (Bernard and Thomas, 1989; Hirshleifer and Teoh, 2003; Barber and Odean, 2008; DellaVigna and Pollet, 2009; Cohen and Lou, 2012; Tetlock, 2014; Cohen, Malloy, and Nguyen, 2020). Our paper contributes to this strand of literature by showing that changing components of net income, without adding new information to financial statements, induces large stock price responses because of investor inattention. Furthermore, we construct a profitable trading strategy that exploits these predictable return patterns. These results also contribute to the literature on what information investors fail to properly account for (Feldman, Govindaraj, Livnat, and Segal, 2010; Brown and Tucker, 2011; Tetlock, 2011).

We add to the emerging literature on investor inattention's influence on managers' decisions in two ways (Kempf, Manconi, and Spalt, 2017; Christensen, Floyd, Liu, and Maffett, 2017; Gilje, Gormley, and Levit, 2020; Fich and $\mathrm{Xu}, 2021$ ). First, we show that investor inattention distorts firms' investment allocation decisions, which has never been explored before (Roychowdhury, Shroff, and Verdi, 2019: Blankespoor et al., 2020). Second, we propose a new mechanism that links investor inattention to changes in firm behavior, which is the interaction between inattention-induced stock 
price discounts and managers' incentive to maximize their firms' s tock prices.

Lastly, our paper contributes to the literature that studies insurers' portfolio choices. Previous studies show that operating risks, financial conditions, changes in regulations, and accounting treatments affect i nsurers' portfolio choices and their investment asset prices ( Ellul, Jotikasthira, and Lundblad, 2011; Ellul, Jotikasthira, Lundblad, and Wang, 2015; Becker and Ivashina, 2015; Chen, Sun, Yao, and Yu, 2020; Ge and Weisbach, 2021; Girardi, Hanley, Nikolova, Pelizzon, and Sherman, 2021; Massa and Zhang, 2021; Becker, Opp, and Saidi, 2021). We extend this literature by investigating whether the placement of information in insurers' financial statements affects their portfolio decisions. We find that moving changes in equity UGL above the net income line reduces insurers' willingness to invest in equity securities.

\section{Institutional Background}

Historically, under SFAS 115 (1993), equity securities could be classified as either available-for-sale (AFS) or trading securities, depending on the firm's intended purpose of holding these securities. Trading securities were those purchased and held for the purpose of selling them in the near term, while the rest were classified as AFS securities. Note that bond securities were allowed an additional third classification: held-to-maturity (HTM). Both trading and AFS securities were recorded on the balance sheet at fair value but were treated differently on the income statement. For trading securities, changes in unrealized gains and losses were included in net income. For AFS securities, changes in UGL were excluded from net income and, instead, included in other comprehensive income (OCI), which is a separate category of income that FASB created to shield net income from certain items.3 When AFS equity securities were sold or experienced other than temporary value impairments (OTTI), the related UGL amount was then recycled from OCI to net income.

In January 2016, FASB eliminated the AFS classification option for equity securities in its Accounting Standards Update (ASU) 2016-01, Financial Instruments-Overall (Subtopic 825-10): Recognition and Measurement of Financial Assets and Financial Liabilities. This update is effective for fiscal years beginning after December 15, 2017, for public business entities. Thus, changes in UGL on all equity securities must now flow through net income. ASU 2016-01 does

\footnotetext{
${ }^{3}$ Items reported in OCI include foreign currency translation adjustments and changes in pension net assets.
} 
not change the accounting treatment for debt securities, and so firms continue to have the option to classify debt securities as either trading, AFS securities or HTM securities, and can thus report changes in UGL on debt securities in either net income or OCI 4 FASB argues that recognizing changes in the fair value for equity investments through net income provides users of financial statements with decision-useful information. According to the FASB, this is because in most cases, the total realizable value of equity investments can be realized by selling them, while the total realizable value of debt instruments is realized through the collection of interest and principal.

The FASB received 150 comment letters when it released the exposed draft in 2013. The majority of comment letters were submitted by companies and associations from the financial sector and non-financial firms that have large investment portfolios. Some companies did not support the idea that equity securities should be measured at fair value through net income (FV-NI). They argued that the FV-NI model would not reflect their investment strategy, would create volatility in their income statements, is decision-irrelevant for investors, and may even distract investors from the company's core business results. For example, the American Insurance Association, whose members provide property and casualty insurance, wrote that FV-NI "reflects unnecessary volatility in the income statement and therefore is not decision-useful." Insurance companies such as AIG and Nationwide expressed concerns that the FV-NI model would increase earnings volatility and is not consistent with their investment strategy, which is more long term in nature.

Non-financial firms that invest large sums of money in equity securities also expressed similar concerns. Google and IBM stated that including changes in UGL in net income is inconsistent with their investment goals, would create earnings volatility, and detract investors' attention from their core activities. Additionally, rating agencies such as Standard \& Poor's Ratings Services did not agree with the FV-NI model. They believed that if a company does not hold equity securities for frequent trading purposes, it should report fair-value changes related to its equity securities in OCI, rather than in net income.

As a concrete example of the concerns outlined above, we show excerpts of income statements in Figure 1 for a property and casualty insurer, Old Republic International, before and after the rule change. We can see that after the rule change, the company began including changes in UGL on equity securities in net income. In this case, changes in UGL on equity securities was negative

\footnotetext{
${ }^{4}$ ASU 2016-01 also contains other amendments, but they do not affect the interpretation of our analyses.
} 
enough that it caused net income, which otherwise would have been positive, to be negative in the quarter.

\section{Data}

This paper uses data from several sources. Our first data source is companies' 10-Q and 10-K filings, from which we hand-collect data on insurance companies' changes in unrealized gains and losses (UGL) on equity securities, which is unavailable in standard databases. We use the data to study differential stock return reactions to equity UGL in the pre- and post-ASU 2016-01 periods. We use changes in UGL on insurers' fixed income investments as control variables in our regressions.

Public companies that follow US GAAP report their investments' UGL positions on a quarterly basis. In the pre-period, we calculate changes in UGL on equity investments that stem from stock price movements as the quarterly change in equity UGL, adjusted for insurers' trading activities and OTTI. Changes in equity UGL come from three sources: changes in stock prices, insurers' trading activities, and OTTI. The latter two are adjustments made to accounting accounts and are unrelated to fluctuations in the market value of stocks 5 Specifically, changes in UGL on equity investments are calculated as the quarterly change in equity UGL, plus any net capital gains and losses resulting from sales of equity securities, less any OTTI recognized on equity securities. In the post-period, firms generally report the exact amounts of changes in equity UGL, which we also hand-collected from insurers' 10-Q and 10-K filings.

The second data source is SNL Financial, a component of the S\&P Global Market Intelligence database. This database contains financial data on insurance companies, both at the parent and subsidiary levels. Data on publicly traded parent companies are reported on a quarterly basis in accordance with US GAAP and come from the Securities and Exchange Commission (SEC). Data on insurance subsidiaries are reported on an annual basis and come from National Association of Insurance Commissioners (NAIC) filings. We use parent-level data for our return reactions analysis because we need a one-to-one mapping between firms and stock tickers. We use subsidiary-level data for our equity investment allocation analysis for two reasons. First, the quality of equity investment data is better at the subsidiary-level, which allows us to be better able to adjust for

\footnotetext{
${ }^{5}$ Appendix A.2 provides an example of the adjustments of trading activities and OTTI. Our results are qualitatively and quantitatively similar when we do not make these adjustments.
} 
mergers and acquisitions (M\&A) activities.6 Second, with subsidiary-level data, we can examine equity investment allocation across different business lines ( e.g., property and casualty, life, and health), which exhibit substantial heterogeneity in investment capital allocation. analyst forecast data from I/B/E/S to construct our measure of core EPS surprise. Stock returns data are from the Center for Research in Security Prices (CRSP).

From these data sets, we construct two samples of insurance companies. The first sample is used to study differences in return reactions to changes in equity UGL before and after ASU 2016-01. This sample consists of company-quarter pairs between 2015Q1 and 2020Q3. The sample ends in 2020Q3 because stock return data associated with announcements of 2020Q4's earnings were unavailable when we constructed the sample. We require companies to (1) list their stocks on a US stock exchange and be headquartered in the US; (2) report changes in equity UGL or sufficiently granular data that allow us to calculate changes in equity UGL (3) be followed by at least one sell-side analyst; (4) have December fiscal year-ends; and (5) classify more than 50\% of their equity investments as AFS in the pre-period.8 We exclude Berkshire Hathaway from our analyses due to its unique business model. Table 1 presents summary statistics for the first sample. Roughly half of the sample is made up of property and casualty insurance companies. Life and health insurance companies account for approximately a quarter of our sample. The rest are multi-line insurers. Insurers, on average, allocate $4 \%$ of their investment capital to public equities.

The second sample is used to study the impact that ASU 2016-01 has on equity investment allocation. The sample period runs from 2015 to 2020. In this sample, insurance subsidiaries owned by publicly traded insurance parent companies are assigned to the treatment group and insurance subsidiaries owned by privately held parents are assigned to the control group. We exclude subsidiaries whose parent companies are listed outside of the US. Similar to before, we

\footnotetext{
${ }^{6}$ For example, in our regressions, we require that insurance subsidiaries do not change public status, and some
} M\&A deals involve specific insurance subsidiaries of insurance companies.

${ }^{7}$ For example, the average property and casualty insurance company allocates $10 \%$ of its investment portfolio to publicly traded stocks, while the average life insurance company allocates $4 \%$. The businesses are quite different as well. For example, life and health insurers tend to have longer-term liabilities such as annuities, while property and casualty companies tend to have shorter-term liabilities such as auto insurance contracts.

${ }^{8}$ ASU 2016-01 affects the recognition of changes in UGL associated with public stock holdings classified as AFS, but it does not affect the recognition of changes in UGL associated with public stock holdings classified as trading securities. The changes in UGL on trading securities are recognized in net income before and after the implementation of ASU 2016-01. All results are quantitatively similar when we include companies that classify more than $50 \%$ of their public stock holdings as trading securities. Note also that we remove several companies that adopted the rule change later than 2018. 
exclude companies that classify more than $50 \%$ of their equity investments as trading securities and subsidiaries owned by Berkshire Hathaway.

Table 2 presents summary statistics for the second sample. This sample contains slightly fewer than 18,000 subsidiary-year observations. Sixty-one percent of the sample is made up of property and casualty insurance subsidiaries, while the rest are life or health insurance subsidiaries. The average insurance subsidiary allocates $67 \%$ of its capital to fixed income securities, $21 \%$ to cash and cash-like instruments, $8 \%$ to publicly traded stocks, and the rest to real estate, mortgage loans, contract loans, and alternatives, such as hedge funds and private equity funds. These statistics highlight that publicly traded stocks make up a non-trivial part of insurance companies' investment portfolios.

\section{Model}

In this section, we build a model to demonstrate how summary earning measures affect inattentive investors' decisions and stock prices. We also show that if the firm's manager aims to maximize the firm's stock price, then summary earning measures can ultimately impact the firm's investment allocation decision.

\subsection{Setup}

There is a continuum of risk-averse investors with mean-variance preferences, where $c$ is the terminal consumption:

$$
E^{\phi}(c)-\frac{\tau}{2} \operatorname{Var}^{\phi}(c)
$$

Investors can be attentive or inattentive. There are two streams of earnings: operating and financial income, which we describe in more detail below. While attentive investors can fully understand and differentiate the persistence and informativeness of the two earnings components, inattentive investors cannot tell the two components apart. Inattentive investors ignore the components and take the summary earnings number as the sole input when updating their estimation

of firm value. We also assume that inattentive investors cannot infer from the stock price that their 
valuation is sub-optimal. We use superscript of $\phi \in\{i, a\}$ to denote the beliefs of inattentive and attentive investors, respectively.

There can be many reasons for such inattention. For example, investors may lack the necessary training to understand the difference between the two earnings streams or lack the time and resources to acquire the necessary information. In addition, the financial media may emphasize only summary earnings measures, leading to investor inattention.

Earnings: The firm has two streams of earnings, $\left\{e_{1}, e_{2}\right\}$. We can think about them as operating income and financial income, which are independent from each other. They have different persistence and thus are applied with different earnings multiples for valuation. Specifically, operating income $e_{1}$ has a valuation multiple of $\rho_{1}$, and follows a normal distribution with mean $\mu_{1}$ and variance $v_{1}$. Financial income $e_{2}$ has a valuation multiple of $\rho_{2}$ and follows a normal distribution with mean $\mu_{2}$ and variance $v_{2} !^{9}$ We assume that valuation multiples are common knowledge. Thus the total firm value is:

$$
\theta=\rho_{1} e_{1}+\rho_{2} e_{2}
$$

Operating income, $e_{1}$, is measured with noise, i.e., $x_{1}=e_{1}+\epsilon_{1}$, with $\epsilon_{1} \sim N\left(0, \sigma_{1}\right)$. Financial income is also measured with noise, i.e., $x_{2}=e_{2}+\epsilon_{2}$, with $\epsilon_{2} \sim N\left(0, \sigma_{2}\right)$. Under the regime of excluding financial income, the earnings number is $y_{A}=x_{1}$. Under the regime of including financial income, the earnings number is $y_{B}=x_{1}+x_{2}$. While attentive investors can digest both versions of $y$ and its components $x_{1}$ and $x_{2}$, inattentive investors can only focus on the summary measure, $y \in\left\{y_{A}, y_{B}\right\}$, but not its components. For simplicity, we assume that there is no private information. Both streams of income, $x_{1}$ and $x_{2}$, are reported under both regimes. The only difference between the two regimes is how these streams of income are aggregated into earnings $y$. The supply of securities is $s$, which is normally distributed with mean $\bar{s}$ and variance $v_{s}$.

\footnotetext{
${ }^{9}$ One way to motivate the earnings multiples: Operating income has persistence of $\gamma_{1}$ and financial income has persistence of $\gamma_{2}$. As a result, the earnings multiple is $\rho_{1}=\frac{1}{1-\gamma_{1}}$ for operating income and $\rho_{2}=\frac{1}{1-\gamma_{2}}$ for financial income. In the case where the financial income has positive, zero, or negative persistence, we would have $\rho_{2}>1$, $\rho_{2}=1$, or $\rho_{2}<1$, respectively.
} 
The Manager: The firm's manager chooses $\mu_{2}$, the expected amount of income from financial assets. The expected amount of operating income is predetermined and so is $\mu_{1}$. These investment amounts are observable. Because the manager's tenure ends before the final payoff is realized, the manager aims to maximize the interim stock price at $t=3$.

To capture the idea that financial assets also carry some risks, we assume that higher expected financial income leads to higher volatility, that is, $\frac{\partial v_{2}}{\partial \mu_{2}}>0$. To ensure an interior solution, we also assume that $\frac{\partial^{2} v_{2}}{\partial \mu_{2}^{2}}>0$.

Timeline: At $t=1$, the manager chooses $\mu_{2}$. At $t=2$, public information arrives about the firm's earning and its components. At $t=3$, investors trade and market price is determined. At $t=4$, payoffs are realized.

$$
\left\{x_{1}, x_{2}\right\} \text { realized; firm reports earnings } y \quad \text { Payoffs realized }
$$

Manager chooses $\mu_{2}$ Investors trade and price is set

$\begin{array}{llll}1 & 1 & 1 & 4\end{array}$

\subsection{Analysis}

We use backward induction to solve the model. First, we solve for the market-clearing price at $t=3$ and characterize how the price discount varies with investor inattention. Then we move to $t=1$ and solve for the manager's optimal investment amount in financial assets.

4.2.1 Market Price at $t=3$. Since investors, indexed by $j$, have mean-variance utility, their demand for the security is:

$$
D_{j}^{\phi}=\frac{1}{\tau} \frac{E_{j}^{\phi}(\theta-p)}{\operatorname{Var}_{j}^{\phi}(\theta)},
$$

where $\theta=\rho_{1} e_{1}+\rho_{2} e_{2}$. Then the market-clearing condition implies that: 


$$
\begin{aligned}
s & =\int D_{j}^{\phi} d j \\
& =\kappa \times D_{j}^{i}+(1-\kappa) \times D_{j}^{a} \\
& =\frac{\kappa}{\tau} \frac{E_{j}^{i}(\theta-p)}{\operatorname{Var}_{j}^{i}(\theta)}+\frac{1-\kappa}{\tau} \frac{E_{j}^{a}(\theta-p)}{\operatorname{Var}_{j}^{a}(\theta)} .
\end{aligned}
$$

Note that the two kinds of investors and they value the firm differently. Attentive investors utilize information fully, while inattentive investors only process the information in the summary earnings number and cannot distinguish the differences between its components.

Lemma 1. At $t=2$, the market price of the stock is

$$
p=w E_{j}^{i}(\theta)+(1-w) E_{j}^{a}(\theta)-\xi s
$$

where $\xi=\frac{\tau}{\frac{\kappa}{\operatorname{Var}_{j}^{i}(\theta)}+\frac{1-\kappa}{\operatorname{Var}_{j}^{a}(\theta)}}$ and $w=\frac{\kappa}{\operatorname{Var}_{j}^{i}(\theta)} /\left(\frac{\kappa}{\operatorname{Var}_{j}^{i}(\theta)}+\frac{1-\kappa}{\operatorname{Var}_{j}^{a}(\theta)}\right)$.

Lemma 1 shows that the equilibrium stock price is a weighted average of the two investor groups' assessment of firm value, minus a discount. The weight, $w$, is positively related to the proportion of inattentive investors, $\kappa$, and negatively related to their residual uncertainty, $\operatorname{Var}_{j}^{i}(\theta)$, which is the remaining uncertainty regarding firm value, conditional on the observed signals. Generally, the more uncertain a group is, the less aggressively it would trade, and thus the smaller its impact on the equilibrium stock price.

Proposition 1. Suppose that $\kappa>0$. The return response to the financial income component is higher under the regime that includes financial income than under the regime that excludes it.

While conventional theory holds that rational investors would not be influenced by the inclusion of financial income as long as they are disclosed, inattentive investors do respond to it. Hence, inclusion of financial income would make stock prices more sensitive to changes in financial income. 
Stock price discount increases with the risk-aversion factor $\tau$ and also with both groups' residual uncertainty regarding firm value. This result is intuitive because more risk-averse investors should require a larger price discount for bearing more uncertainty.

Proposition 2. Holding fixed the investment amount in financial assets, the expected price discount is as follows:

$$
\xi \bar{s}=\frac{\tau}{\frac{\kappa}{\operatorname{Var}_{j}^{i}(\theta)}+\frac{1-\kappa}{\operatorname{Var}_{j}^{a}(\theta)}} \bar{s} .
$$

All else equal, (1) the price discount increases with $\kappa$, the proportion of inattentive investors. (2) The price discount is higher in the regime that includes financial income than in the regime that excludes it, if and only if

$$
\frac{v_{1} \rho_{1}}{v_{1} \rho_{1}+v_{2} \rho_{2}}>\sqrt{\frac{v_{1}+\sigma_{1}}{v_{1}+\sigma_{1}+v_{2}+\sigma_{2}}} .
$$

A stock price discount arises because investors are risk averse, and larger residual uncertainty leads to larger discounts. Compared to attentive investors who fully digest all information, inattentive investors would increase the price discount because they do not fully utilize information and have larger residual uncertainty. Thus, the price discount is higher when the share of inattentive investors $(\kappa)$ is higher.

The second part of the proposition holds the amount of financial assets constant, and compares the price discounts under the two regimes $\left(\xi_{\text {inclusive }}\right.$ and $\left.\xi_{\text {exclusive }}\right)$. The inclusive regime's price discount is relatively larger when (1) $\sigma_{2}$ (noise in measuring financial income) is larger and/or (2) $\frac{\rho_{2}}{\rho_{1}}$ (the relative persistence of financial income to operating income)is smaller. The intuition is as follows. Note that the measurement of financial income affects net income only in the inclusive regime. To inattentive investors, as $\sigma_{2}$ increases, the inclusive regime provides a noisier summary measure, while the exclusive regime does not. As $\rho_{2}$ decreases, financial income becomes less persistent and more different from operating income. As a result, inattentive investors mixing up these two streams of income end up with a less informative measure for the firm's total value and demand a higher price discount. 
This proposition highlights the dilemma around whether to include financial income into net income. While its inclusion provides a more complete picture about shareholders' wealth change that is realized or realizable in that period, it nonetheless might make net income number less informative about the firm's fundamental value. This is because interim fluctuations in financial asset values tell investors little about the firm's future operating performance. Inattentive investors end up with a less accurate understanding of the firm's overall value because they cannot tell the two income components apart.

4.2.2 Manager's Investment at $t=1$. Anticipating how the market prices the firm, the manager chooses how much to invest into financial asses. We make a simplifying assumption that $\kappa$ is sufficiently large that market pricing is mostly determined by inattentive investors. The manager's problem is:

$$
\max _{\mu_{2}} E\left(p \mid \mu_{2}\right)
$$

Ex ante, the expected firm price is $\rho_{1} \mu_{1}+\rho_{2} \mu_{2}-\xi \bar{s}$. The manager weighs the marginal benefit and marginal cost of investing in financial assets to determine the optimal investment amount. Each unit of additional investment in the financial asset leads to an increase in firm value of $\rho_{2}$, but also leads to a higher price discount by increasing the uncertainty in total firm value $\left(\frac{\bar{s}}{\tau} \frac{\partial v_{2}}{\partial \mu_{2}} \rho_{2}^{2}\right)$. This impact is mitigated to the extent net income informs investors about firm value. The two accounting regimes differ in how informative they can be. Under the exclusive regime, inattentive investors never learn about financial income and its related uncertainty is never resolved. However, under the inclusive regime, inattentive investors learn about the sum of the two components, but at the expense of not being able to tell them apart. Thus, if the inclusive regime leads to lower (higher) marginal resolution of residual uncertainty, it would lead to higher (lower) marginal cost for investing in financial assets. We can compare the two cases below.

Proposition 3. Assume $\kappa$ is sufficiently large and denote $v_{2}^{e x}$ be the variance of financial income under the exclusive regime. Then a sufficient condition for the manager to hold less financial assets 
under the inclusive regime than under the exclusive regime is as follows:

$$
\frac{\rho_{2}}{\rho_{1}}<\frac{v_{1}}{2 v_{1}+v_{2}^{e x}+2 \sigma_{1}+2 \sigma_{2}} .
$$

Comparing the two regimes, as firms invest more in financial assets, financial income becomes more volatile. It has two impacts on the desirability of inclusive regime. On the one hand, learning about financial income becomes more important to gauge the firm value, which makes inclusive regime more useful. On the other hand, it introduces volatility into net income, which is not very informative about firm's total value, and impairs net income's value as a summary measure for inattentive investors. This negative impact is more pronounced when (1) financial income has low persistence relative to operating income (2) when financial income is measured more accurately. When that is the case and when inattentive investors play an important role in the market, firms will reduce investment in financial assets under the inclusive regime.

The above proposition identifies the conditions under which including financial income in net income can lead to less investment in the first place. Applying to our empirical setting, unrealized gains and losses on equity securities have low persistence relative to operating income because the equity market is relatively efficient and equity UGL is mostly unpredictable. Also, the market value of equity securities can be measured with high reliability. Thus, the conditions identified in the above proposition are very likely to be met in our setting and we predict that, under the inclusive regime, public insurance firms will cut back on investments in equity securities.

\subsection{Testable Hypotheses}

While the model is presented in general terms, it applies well to our study of ASU 2016-01. We can think of insurance companies' net income as the sum of two streams: income from operations, and income from changes in equity UGL. The model gives us the following predictions.

Hypothesis 1. Insurance companies' earnings become more volatile after the implementation of $A S U$ 2016-01.

Hypothesis 2. Insurance companies' earnings become less persistent after the implementation of ASU 2016-01. 
Hypotheses 1 and 2 are mechanical results from the implementation of ASU 2016-01, which forces public companies to incorporate changes in unrealized gains and losses from equity securities investments into net income. Since financial income (i.e., changes in UGL) from the equity portfolio is more volatile and less persistent than operating income, it follows that insurance companies' earnings in the post-ASU 2016-01 era should be more volatile and less persistent. The last two hypotheses follow directly from Propositions 1 and 3, respectively.

Hypothesis 3. Return responses to unrealized gains and losses on equity securities are higher after the implementation of ASU 2016-01.

Hypothesis 4. After the implementation of ASU 2016-01, public insurance companies reduce their holdings of equity securities, relative to private insurance companies.

Hypothesis 4 follows from the reasoning that publicly traded insurance companies are treated by the accounting rule change and respond accordingly. On the other hand, privately held insurance companies are unaffected by ASU 2016-01.

\section{Empirical Strategy}

This section describes the empirical strategies that we use to test hypotheses 3 and 4 . We postpone the discussion on the empirical tests for hypotheses 1 and 2 to the results section because we use simple descriptive statistics and t-tests to evaluate them.

\subsection{Return Response Test}

Hypothesis 3 states that return responses to changes in unrealized gains and losses on equity securities are larger after the implementation of ASU 2016-01. We use fixed effects panel regressions to test this hypothesis. Specifically, we run variants of the following regression: 


$$
\begin{aligned}
C A R_{i t}=\alpha & +\beta_{1}{\text { Equity } U G L_{i t}} \\
& +\beta_{2}{\text { Equity } U G L_{i t} \times \text { Post }_{t}} \\
& +\beta_{3} \text { EPS Surprise } \\
& \\
& +\beta_{4} \text { EPS Surprise } i t \times \text { Post }_{t} \\
& +\gamma^{\prime} \mathbf{x}_{\mathbf{i t}}+\text { Firm FE }+ \text { YearQuarter FE }+\epsilon_{i t} .
\end{aligned}
$$

$i$ indexes firms and $t$ indexes year-quarters. T he dependent variable is firm $i$ 's cumulative abnormal return (CAR), with respect to the CAPM or the Carhart four-factor model (Carhart, 1997), calculated over various time frames around the firm's earnings a nnouncement date. Equity $U G L_{i t}$ is firm i's, per share, interquarter change in unrealized gains or losses on its equity investments, adjusted for insurers' trading activities and OTTI, and scaled by firm $i$ 's share price observed at the end of the most recent quarter $t$. Post $t_{t}$ is an indicator variable, which equals 1 for the time period after ASU 2016-01 was implemented, 2018Q1 onward, and zero otherwise. EPS Surprise $i t$ is defined a s the difference between the actual reported core EPS and analysts' consensus, scaled by firm $i$ 's share price observed at the end of the most recent quarter. $\mathbf{x}$ it is a vector of firm-quarter control variables.

In this regression specification, $\beta_{1}$ i s the return reaction to changes in equity UGL in the pre-ASU 2016-01 period. $\beta_{1}+\beta_{2}$ is the return reaction to changes in equity UGL in the post period. $\beta_{3}$ is the return reaction to core EPS surprise in the pre-ASU 2016-01 period. $\beta_{3}+\beta_{4}$ is the return reaction to core EPS surprise in the post-period. With the identifying assumption that this rule change shock is orthogonal to other shocks that may have impacted both CAR and equity UGL in the same time period, the effect that ASU 2016-01 has on abnormal stock returns is identified by the interaction term Equity $U G L_{i t} \times$ Post $_{t}$. Hypothesis 3 predicts that $\beta_{2}$ should be positive and statistically different from zero.

Our model proposes that the return reaction to equity UGL should increase in the post-period because of inattentive investors' overreaction to changes in net income that stem from changes in equity UGL. We can provide empirical evidence for this mechanism by examining the differential effects that ASU 2016-01 has on companies with many equity analysts covering them versus those that have few. Since equity analysts help investors process information (Balakrishnan, Billings, 
Kelly, and Ljungqvist, 2014), the inattention problem should be attenuated when companies have more analysts covering them. Specifically, the change in post-period return reaction should be relatively muted for this group of companies. We run variants of the following panel regression to test this conjecture:

$$
\begin{aligned}
& C A R_{i t}=\alpha+\beta_{1} \text { Equity } U G L_{i t} \\
& +\beta_{2} \text { Equity } U G L_{i t} \times \text { Post }_{t} \\
& +\beta_{3} \text { High Cov }_{i t} \times \text { Post }_{t} \\
& +\beta_{4} \text { Equity } U G L_{i t} \times H i g h \operatorname{Cov}_{i t} \\
& +\beta_{5} \text { Equity } U G L_{i t} \times \text { High Cov }_{i t} \times \text { Post }_{t} \\
& +\gamma^{\prime} \mathbf{x}_{\mathbf{i t}}+\text { Firm FE }+ \text { YearQuarter FE }+\epsilon_{i t} .
\end{aligned}
$$

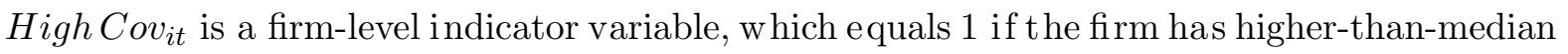
average number of analysts covering it, where average number of analysts is calculated for each company, using data from 2015 to 2020. The model predicts that $\beta_{5}$ should be negative and statistically different from zero.

\subsection{Equity Investment Allocation Test}

Hypothesis 4 states that, in response to ASU 2016-01, public insurance companies should reduce their equity investment allocations. We use a difference-in-differences ap proach to ev aluate this hypothesis. The unit of analysis in this section is an insurance subsidiary. We consider insurance subsidiaries owned by publicly traded parent companies as the treatment group because their publicly traded parents are subjected to ASU 2016-01. We use insurance subsidiaries owned by privately held parent companies as the control group because they are not subjected to the rule change.

An important assumption in the difference-in-differences framework is that subjects cannot change their treatment status. In other words, members of the treatment group cannot switch to the control group and vice versa. To ensure that this assumption plausibly holds in our analysis, we only include subsidiaries whose parents never change their public/private status during the sample period. Although the decision to go public or be taken private is endogenous, we are making the 
implicit assumption that these companies did not change their public/private status during our sample period because of some exogenous frictions that are unrelated to our study.

Another important assumption in the difference-in-differences framework is the parallel trend assumption. In this context, the parallel trend assumption is that changes in equity investment allocation across subsidiaries in the treatment and control groups would be the same, in the absence

of ASU 2016-01. We provide visual support for this assumption in Figure2, which plots each group's average percentage of total investment dollars allocated to public stocks. Each line is scaled by its respective 2017 value. It is clear from the picture that the changes in equity allocation among the treated and control group firms are very similar in the pre-ASU 2016-01 period and only begin to diverge in the post period.

Using the difference-in-differences setup, we test hypothesis 4 by running variants of the following regression:

$$
E Q A_{i t}=\alpha+\beta_{1} \times U S \text { Public }_{i} \times \text { Post }_{t}+\gamma^{\prime} \mathbf{x}_{\mathbf{i t}}+S u b F E+\text { Year FE }+\epsilon_{i t} .
$$

$i$ indexes subsidiaries and $t$ indexes years. EQA is the subsidiary's equity investment allocation, which is calculated as the total amount of capital invested in publicly traded stocks divided by the total amount of capital in the subsidiary's investment portfolio. US Public $c_{i}$ equals 1 for subsidiaries that belong to a US-based insurance parent company that is publicly traded on a US stock market exchange and zero for subsidiaries owned by private companies. $\mathbf{x}_{\mathbf{i t}}$ is a vector of subsidiary-year control variables, which include log of total assets, ROE, leverage, and risk-based capital (RBC) ratio. Hypothesis 4 predicts that $\beta_{1}$ should be negative and statistically different from zero.

\section{$6 \quad$ Results}

\subsection{Earnings Volatility}

This subsection provides empirical support for hypothesis 1 . We begin by examining how GAAP EPS and GAAP EPS excluding changes in equity UGL behave before and after ASU 2016-01 was implemented. Figure 3 plots mean GAAP EPS and mean GAAP EPS excluding equity UGL across all public insurers for each quarter between 2011 and 2020. The sample includes all company- 
quarters with available stock price and total assets data, except for Berkshire Hathaway 10 The red line plots mean GAAP EPS excluding equity UGL and the blue line plots mean GAAP EPS. These two lines are identical in the pre-ASU 2016-01 period. After ASU 2016-01 was implemented, mean GAAP EPS became much more volatile because it includes changes in unrealized gains and losses on equity investments.

Next we compare the average standard deviation of quarterly GAAP EPS across the pre and post periods. In the pre-period (2015 to 2017), for each insurer, we calculate the standard deviation of its quarterly GAAP EPS and take the average. We repeat the procedure for the post period and for GAAP EPS excluding equity UGL. Figure 4 plots the three averages, along with their 95\% confidence intervals. Qualitatively consistent with what we find in Figure 3, the volatility of GAAP EPS excluding changes in equity UGL is essentially identical across the two time periods, while average GAAP EPS volatility increased markedly after ASU 2016-01 was implemented. A one-tailed t-test shows that the difference between the first and third dots is statistically significant at the $10 \%$ level.

\subsection{Earnings Persistence}

Hypothesis 2 states that earnings persistence should decrease after the implementation of ASU 2016-01. Using the same sample of public insurance companies as in Figure 4, we test for changes in earnings persistence. We measure each public insurer's earnings persistence by running the following regression:

$$
E P S_{q+1}=\alpha+\beta \times E P S_{q}+\epsilon
$$

Next quarter's GAAP EPS is regressed onto the current quarter's GAAP EPS and $\beta$ captures the degree of autocorrelation between the two. We estimate $\beta$ for each insurer's GAAP EPS excluding equity UGL and GAAP EPS. We perform this procedure for both the pre and post periods. Then, we calculate mean persistence as the average of these regression coefficients for GAAP EPS in the pre-period, GAAP EPS in the post-period, and GAAP EPS excluding changes in equity UGL in the post-period.

\footnotetext{
${ }^{10}$ We also apply similar filters mentioned earlier, such as including only firms with AFS equity securities comprising at least $50 \%$ of equity securities before the rule change.
} 
Figure 5 plots the three resulting mean persistence values. Persistence in GAAP EPS including equity UGL is significantly lower than both GAAP EPS in the pre-period and GAAP EPS excluding equity UGL in the post period. A one-tailed t-test shows that the difference between GAAP EPS in the pre-period and GAAP EPS in the post-period is statistically significant at the $5 \%$ level, consistent with our model's assumption that the summary earnings measure became more volatile and less persistent under the inclusive regime, i.e., post-ASU 2016-01, which increased the perceived residual uncertainty for inattentive investors.

\subsection{Return Reaction Results}

Hypothesis 3 states that return responses to changes in equity UGL should be larger in the postASU 2016-01 period. To test this hypothesis, we estimate variants of regression Equation 1. Table 3 presents OLS regression results where CAPM cumulative abnormal returns (CAR) over various horizons are regressed onto the interaction term between Equity UGL and a post-ASU 2016-01 indicator variable. The first column of Table 3 presents results for short-term $(t-1$ to $t+1)$ CAPM CAR around each company's earnings announcement date $t$. The coefficient on the interaction term is positive and statistically different from zero, which is consistent with hypothesis 3 . The interpretation is that, in the post-ASU 2016-01 period, a 1 percentage point increase in scaled equity UGL increases short-term CAPM CAR by 87 (1.49 - 0.62) bps.

Column 2 presents regression results where we add common control variables such as core EPS surprise, log market capitalization, leverage ratio, market to book ratio, and CAPM beta. The Equity UGL coefficient is no t st atistically di fferent fro m zer o, whi le the coe fficient on Eq uit y UGL $\times$ Post is statistically significant and quantitatively similar to that in Column 1 . This specification suggests that, in the pre-period, investors do not react to changes in equity UGL, but they do so

in the post-period. A 1 percentage increase in scaled equity UGL per share increases short-term CAPM cumulative abnormal returns by 73 bps.

As a placebo test, we include changes in unrealized fixed income gains and losses and this

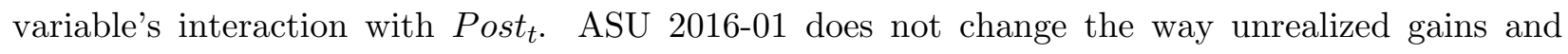
losses from fixed income investments are presented to investors and so we do not expect investors to react more to changes in these unrealized gains and losses in the post-period. In line with this reasoning, the coefficients on both the st and-alone and in teraction terms are not statistically 
different from zero.

Columns 3 through 6 presents results for longer horizons of CAPM CAR. Medium-term CAPM CAR is calculated from $t-1$ to $t+10$. Long-term CAPM CAR is calculated from $t-1$ to $t+20$. The results are quantitatively and qualitatively similar across all columns, which suggests that return reactions associated with changes in equity UGL, in general, do not correct themselves over longer time horizons. Table 4 presents OLS regression results where we repeat the previous exercise using the Carhart four-factor CAR. We find very similar results, which shows that this empirical pattern is robust to the benchmark asset pricing model.

To further study return dynamics around earnings announcement dates, Figures 6 and 7 plot high, medium, and low Equity UGL portfolios' CAPM cumulative average abnormal returns (CAAR) dynamics around earnings announcement dates in the pre- and post-periods, respectively. To construct the pre-period plot, we begin by sorting all company-quarters by their scaled change in equity UGL per share values. Company-quarters in the top tercile of the distribution are allocated to the high change in equity UGL portfolio, the middle tercile company-quarters are allocated to the medium portfolio, and the bottom tercile to the low portfolio. In the last step, we plot each portfolio's CAPM CAAR from $t-30$ to $t+60$. We repeat this procedure to construct the postperiod plot. Note that these are not plots of CAPM CAAR from a trading strategy. Instead, these are plots of returns dynamics during quarters when the broader stock market returns are positive versus when they are negative.

Figure 6 shows that, in the pre-period, there is little visible difference between the high portfolio's CAPM CAAR and the low portfolio's CAPM CAAR, both before and after the earnings announcement date. Using t-tests to evaluate differences in means, we find that the average high minus low CAPM CAAR is never statistically different from zero. This result suggests that there is no difference in returns across equity UGL portfolios in the pre-period.

Figure 7 presents CAPM CAAR dynamics around earnings announcement dates in the postperiod. Similarly to the pre-period, graphically, there is little difference in CAPM CAARs between the high and low equity UGL portfolios prior to earnings announcements. However, the average post-earnings announcement difference in CAPM CAAR is large. High change in equity UGL portfolio's CAPM CAAR jumps up at $t=0$, while low change in equity UGL portfolio's CAPM CAAR falls, suggesting that investors react to the information contained in changes in UGL. From 
$t-1$ to $t+10$, the difference in C APM C AAR is $4.55 \%$ and is s tatistically different fr om ze ro at the $1 \%$ level. As time passes, the gap widens. The difference in CAPM CAAR from $t-1$ to $t+40$ is close to $7 \%$. The upward jump in CAPM abnormal returns for the high change in equity UGL portfolio dissipates at around day $t+40$, but the drop in CAPM abnormal returns associated with the low change in equity UGL portfolio continues until day $t+40$ and sustains the gap between the two return series 11

\subsection{Analyst Coverage and Return Reaction Results}

Our model argues that the return reaction results stem from inattentive investors paying attention to changes in UGL in the post-ASU 2016-01 period. To provide support for this mechanism, we estimate variants of Equation 2. This regression tests for differences in post period return reactions with respect to changes in equity UGL between companies with high and low analyst coverage levels. As discussed earlier, analysts synthesize information for the investment community by reporting each company's core performance and its future prospects. Suppose that it is costly for investors to study financial statements, then analysts lower this cost by presenting only the most essential information to investors. Anecdotally, equity analysts that cover insurance companies often provide estimates of core EPS that exclude changes in unrealized gains and losses from equity securities because they believe that such changes are transitory 12 Through the lens of our model, we can think of a sell-side analyst as a vehicle that helps unpack the summary earnings measure for inattentive investors. This service ultimately helps inattentive investors price the firm's stock correctly, i.e., as if they were attentive. With this line of reasoning, it follows that post-period return reactions associated with changes in equity UGL should be smaller for companies with high analyst coverage.

Table 5 presents OLS regression results from estimating variants of Equation 2. Columns 1 through 3 present results for short-term, medium-term, and long-term CAPM CARs. Columns 3 through 6 present results for the Carhart four-factor CARs. The coefficient of in terest is the one on the triple interaction term between Equity UGL, Post, and High Cov. Our model predicts that

\footnotetext{
${ }^{11}$ The results are similar if we, instead, sort stocks every quarter. See the appendix for charts.

${ }^{12}$ We spoke with several analysts who cover the insurance industry. Core EPS excludes items that analysts deem to be one-time in nature such as investment gains and losses, both realized and unrealized. Furthermore, analysts generally use core EPS when projecting earnings and estimating target prices.
} 
this coefficient should be negative and this is the case across all six specifications. For both the CAPM and Carhart four-factor CARs, the coefficient of interest grows more negative at longer time horizons, which suggests that return reactions associated with equity UGL correct themselves more quickly at companies with higher levels of analyst coverage. These results are consistent with the conjecture that investor inattention causes larger return reactions in the post-period.

\subsection{Trading Strategy Results}

The previous sections show that inattentive investors overreact to changes in equity UGL in a systematic way, which means that we can construct a trading strategy that exploits this irrational behavior. This exercise serves to provide additional evidence that return reactions documented in the previous sections are indeed driven by changes in equity UGL. The following trading strategy only involves stocks of insurance companies that have positive equity investment allocations. For a given quarter, if the CRSP value-weighted index return is positive, then, during the following quarter, we buy each insurance company's stock one day before its earnings announcement date and hold the stock for 10 trading days after the earnings announcement. If the CRSP value-weighted index return is negative, then, during the following quarter, we sell short each insurance company's stock one day before each company's earnings announcement date and unwind the position 10 trading days after the earnings announcement date.

Figure 8 plots the weighted average quarterly returns of this trading strategy in the preand post-periods. Stocks are weighted according to the companies' equity allocation percentage such that the weights add up to one in each quarter. The bars plot returns collected from the following quarter. For example, the 2018Q1 bar plots the return from trading activity that occurs during 2018Q2, based on earnings announcements related to 2018Q1. Visually, returns in the pre-period are inconsistent, while returns in the post-period are mostly positive. The average 12-day return, across all company-quarters, is $0.95 \%$ in the pre-period. This number is not statistically different from zero. On the other hand, the average 12-day return in the post-period is $2.5 \%$ and statistically different from zero at the $5 \%$ level. The average equal-weighted 12-day return in the post-period is $1.4 \%$, which suggests that the returns from this trading strategy are driven by insurance companies that hold relatively large amounts of equity securities.

Since we do not have a sufficiently long time series of the strategy's returns data, we cannot 
implement the standard asset pricing test for risk-adjusted returns (Fama and French, 1993). In light of this limitation, we calculate the trading strategy's risk-adjusted returns as the weighted average of the 12-day abnormal returns across all stocks that we trade. Using this methodology, we find that the post period average Carhart four-factor abnormal return for this strategy is $2.4 \%$ and is statistically different from zero at the $1 \%$ level. We do not interpret these results as evidence for a profitable risk-adjusted trading strategy, but, instead, a s suggestive evidence that A SU 2016-01 may have caused the market for insurance companies' stocks to become less efficient.

\subsection{Equity Investment Allocation Results}

This subsection presents the difference-in-differences equity investment allocation regression results that support hypothesis 4. Table 6 presents regression results for variants of Equation 3. Column 1 shows estimates of the difference-in-differences re gression wi thout co ntrol va riables an d fin ds that, after ASU 2016-01 was implemented, the average insurance subsidiary of publicly traded companies decreased its investment in publicly traded securities by 0.47 percentage points. Given that the average public insurance subsidiary allocated $2.6 \%$ of its investment portfolio to public stocks in 2017, this effect is approximately equivalent to an $18 \%$ reduction in total public stock investment.

Column 2 presents regression results where we include additional control variables. The coefficient on the interaction term is similar to the one shown in Column 1, which suggests that the impact that ASU 2016-01 has on public insurers' investment in equity securities is orthogonal to these firm characteristics. Columns 3 and 4 present regression results by insurer type. Column 3 shows the estimation results for property and casualty insurers and finds that the effect documented in column 2 is concentrated among this type of insurers. This result makes sense because the average $\mathrm{P} \& \mathrm{C}$ insurer allocates more investment capital toward public equities than others. In column 4, the coefficient on US Public $\times$ Post is negative and sizable, but not statistically different from zero. The result suggests that ASU 2016-01 may have also impacted life and health insurers' investment portfolios, but we lack the statistical power to detect it.

To show that the results above admit a causal interpretation, we run the following regression to check that the relative drop in equity allocation among treated insurance subsidiaries only occurred after the implementation of ASU 2016-01: 


$$
\begin{aligned}
E Q A_{i t}=\alpha & +\beta_{1} \times \text { US Public } i \times \mathbb{1}(2016)_{t} \\
& +\beta_{2} \times U S \text { Public }_{i} \times \mathbb{1}(2017)_{t} \\
& +\beta_{3} \times U S \text { Public } i \times \mathbb{1}(2018)_{t} \\
& +\beta_{4} \times \text { US Public } \times \mathbb{1}(2019)_{t} \\
& +\beta_{5} \times \text { US Public } i \times \mathbb{1}(2020)_{t} \\
& +\gamma^{\prime} \mathbf{x}_{\mathbf{i t}}+\text { SubFE }+ \text { Year FE }+\epsilon_{i t} .
\end{aligned}
$$

In this specification, US Public is interacted with year indicator variables, using 2015 as the reference year. If the treatment effect occurred after the implementation of ASU 2016-01, then $\beta_{1}$ and $\beta_{2}$ should not be statistically different from zero. Figure 9 plots the coefficients on the interaction terms and their respective $95 \%$ confidence intervals. It is clear from the plot that the treatment effect was realized in 2019 and 2020 ${ }^{13}$ Furthermore, this pattern suggests that the new accounting rule may have had more bite during episodes of high stock market volatility such as the COVID-19 crisis that began in 2020 .

A concern that a shrewd reader may have with the results presented in Table 6 is that systematic differences between insurance subsidiaries owned by publicly traded companies and those owned by privately held companies may bias the estimates. As a robustness check, we construct a propensity score matched sample where each treated subsidiary is matched with the most similar subsidiary from the control group that belongs to the same insurance subindustry (e.g., property and casualty, life, or health). We match subsidiaries on the following 2015 characteristics: log assets, return on equity (ROE), RBC ratio, and leverage.

Table 7 compares average 2015 characteristics between the treated subsidiaries and their control group matches. First, there is no statistical difference between these two groups with regard to the matched variables and investment portfolio size. The key differences arise in each group's investment portfolio allocation. However, the existence of these differences does not necessarily suggest that the difference-in-differences regression estimates from this sample of firms would be biased because these are level differences and not differences in changes. Table 8 presents regression results for variants of Equation 3, using the propensity score matched sample. The overall results

\footnotetext{
${ }^{13}$ Please refer to column 2 of Table $\mathrm{A} 2$ for the accompanying regression results.
} 
are quantitatively and qualitatively similar to those presented in Table6. One key difference is the coefficient on US Public $\times$ Post in column 4 suggests that ASU 2016-01 has no effect on life and health insurance companies' investment allocation decisions.

We interpret these results through the lens of our theoretical model. Managers of insurance companies wish to maximize stock prices. After ASU 2016-01 goes into effect, inattentive investors perceive net income to be more volatile and therefore assign larger discounts to insurance companies' stock prices. With this knowledge of how investors will react, managers choose to decrease investment in publicly traded stocks to lower their companies' earnings volatility.

The plot in Figure 9 shows that treated insurance subsidiaries gradually cut their allocation to publicly traded stocks in 2019 and 2020. In light of this pattern, we use the estimated coefficients from the plot to calculate the partial equilibrium effect that ASU 2016-01 has on publicly traded insurers' aggregate stock allocation $\sqrt{14}$ For this calculation, we assume that the estimated effects are applicable to all insurance subsidiaries that are owned by publicly traded parent companies. As before, we exclude Berkshire Hathaway from the analysis. We find that, relative to the control group, treated insurance subsidiaries cut their equity securities holdings by $\$ 23$ billion in 2020 , which is equivalent to approximately half of the group's total 2020 public stock investment 15 This exercise suggests that ASU 2016-01 distorts insurers' portfolio allocation decisions and potentially decreased their long-run investment returns.

\section{Conclusion}

This paper shows that, through the interaction between stock prices and managers' incentives, inattentive investors' actions can distort companies' investment allocation decisions. Using the insurance industry as a laboratory, we show that inattentive investors' influence on stock prices induces managers to buy less publicly traded stocks, which may lower their companies' long-run investment returns. Lower returns, ultimately, impair insurance companies' ability to underwrite new policies, meet upcoming claims, and help individuals share risks. Since exchange-traded funds

\footnotetext{
${ }^{14}$ Refer to column 2 of Table A2 in the appendix for the accompanying regression results.

${ }^{15}$ Company $i$ 's counterfactual equity allocation dollar amount in year $t$ equals its observed equity allocation percentage plus the estimated coefficient for that year times the total dollar amount in its investment portfolio. Annual aggregate numbers are calculated as the sum of the differences between the counterfactual and observed equity allocation dollar amounts across all insurance subsidiaries owned by publicly traded parent companies.
} 
(ETFs) are generally classified as equity securities under US GAAP, the result also implies that ASU 2016-01 may have slowed the growth of the ETF industry.

More broadly, the results from this paper suggest that the actions of inattentive investors can have implications for the real economy. Darmouni and Mota (2020) show that publicly traded nonfinancial firms do invest in public stocks and, to the extent that managers use stock prices as signals about the value of their firms' growth opportunities, stock price distortions caused by inattentive investors can have important implications for firms' investment decisions and the economy's growth prospects (Foucault and Gehrig, 2008).

With respect to setting accounting standards, our paper helps inform the debate over the merits of ASU 2016-01. FASB implemented the rule change based on the belief that changes in unrealized gains and losses from equity securities investments reflect meaningful changes in the companies' underlying economic conditions because companies can realize these gains and losses immediately by liquidating their equity positions (Financial Accounting Standards Board, 2016). On the other hand, investors, such as Warren Buffett (Buffett, 2018), and sell-side analysts believe that this change would make net income numbers less informative. Our paper provides supporting evidence for the latter view by showing that investors overreact to changes in unrealized gains and losses, which implies that investors are potentially confused by the new net income numbers. 


\section{References}

Balakrishnan, K., M. B. Billings, B. Kelly, and A. Ljungqvist. 2014. Shaping liquidity: On the causal effects of voluntary disclosure. The Journal of Finance 69:2237-2278.

Barber, B. M., and T. Odean. 2008. All that glitters: The effect of attention and news on the buying behavior of individual and institutional investors. The Review of Financial Studies 21:785-818.

Becker, B., and V. Ivashina. 2015. Reaching for yield in the bond market. The Journal of Finance 70:1863-1902.

Becker, B., M. M. Opp, and F. Saidi. 2021. Regulatory forbearance in the US insurance industry: The effects of removing capital requirements for an asset class. Swedish House of Finance Research Paper.

Bernard, V. L., and J. K. Thomas. 1989. Post-earnings-announcement drift: Delayed price response or risk premium? Journal of Accounting Research 27:1-36.

Blankespoor, E., E. deHaan, and I. Marinovic. 2020. Disclosure processing costs, investors' information choice, and equity market outcomes: A review. Journal of Accounting and Economics 70:101344.

Brown, S. V., and J. W. Tucker. 2011. Large-sample evidence on firms' year-over-year MD\&A modifications. Journal of Accounting Research 49:309-346.

Buffett, W. E. 2018. Berkshire Hathaway Inc. 2017 Annual Report. https://www. berkshirehathaway.com/2017ar/2017ar.pdf

Carhart, M. M. 1997. On persistence in mutual fund performance. The Journal of Finance 52:5782.

Chen, X., Z. Sun, T. Yao, and T. Yu. 2020. Does operating risk affect portfolio risk? Evidence from insurers' securities holding. Journal of Corporate Finance 62:101579.

Christensen, H. B., E. Floyd, L. Y. Liu, and M. Maffett. 2017. The real effects of mandated information on social responsibility in financial reports: Evidence from mine-safety records. Journal of Accounting and Economics 64:284-304.

Cohen, L., and D. Lou. 2012. Complicated firms. Journal of Financial Economics 104:383-400.

Cohen, L., C. Malloy, and Q. Nguyen. 2020. Lazy prices. The Journal of Finance 75:1371-1415.

Darmouni, O., and L. Mota. 2020. The Financial Assets of Non-Financial Firms. Available at SSRN 3543802.

DellaVigna, S., and J. M. Pollet. 2009. Investor inattention and Friday earnings announcements. The Journal of Finance 64:709-749. 
Ellul, A., C. Jotikasthira, and C. T. Lundblad. 2011. Regulatory pressure and fire sales in the corporate bond market. Journal of Financial Economics 101:596-620.

Ellul, A., C. Jotikasthira, C. T. Lundblad, and Y. Wang. 2015. Is historical cost accounting a panacea? Market stress, incentive distortions, and gains trading. The Journal of Finance 70:2489-2538.

Engelberg, J. 2008. Costly information processing: Evidence from earnings announcements. In AFA 2009 San Francisco meetings paper.

Fama, E. F., and K. R. French. 1993. Common risk factors in the returns on stocks and bonds. Journal of Financial Economics 33:3-56.

Feldman, R., S. Govindaraj, J. Livnat, and B. Segal. 2010. Management's tone change, post earnings announcement drift and accruals. Review of Accounting Studies 15:915-953.

Fich, E. M., and G. Xu. 2021. The real effects of trend-seeking and extrapolation: Evidence from M\&As. Available at SSRN 2996714.

Financial Accounting Standards Board. 2016. FASB Accounting Standard Update. https://www.fasb.org/jsp/FASB/Document_C/DocumentPage?cid=1176167762170\& acceptedDisclaimer=true.

Foucault, T., and T. Gehrig. 2008. Stock price informativeness, cross-listings, and investment decisions. Journal of Financial Economics 88:146-168.

Ge, S., and M. S. Weisbach. 2021. The role of financial conditions in portfolio choices: The case of insurers. Journal of Financial Economics 142:803-830.

Gilje, E. P., T. A. Gormley, and D. Levit. 2020. Who's paying attention? Measuring common ownership and its impact on managerial incentives. Journal of Financial Economics 137:152178.

Girardi, G., K. W. Hanley, S. Nikolova, L. Pelizzon, and M. G. Sherman. 2021. Portfolio similarity and asset liquidation in the insurance industry. Journal of Financial Economics 142:69-96.

Hirshleifer, D., and S. H. Teoh. 2003. Limited attention, information disclosure, and financial reporting. Journal of Accounting and Economics 36:337-386.

Kempf, E., A. Manconi, and O. Spalt. 2017. Distracted shareholders and corporate actions. The Review of Financial Studies 30:1660-1695.

Massa, M., and L. Zhang. 2021. The spillover effects of Hurricane Katrina on corporate bonds and the choice between bank and bond financing. Journal of Financial and Quantitative Analysis 56:885-913. 
Roychowdhury, S., N. Shroff, and R. S. Verdi. 2019. The effects of financial reporting and disclosure on corporate investment: A review. Journal of Accounting and Economics 68:101246.

Schipper, K. 2007. Required disclosures in financial reports. The Accounting Review 82:301-326.

Song, B., S. Wang, and B. Wheeler. 2021. Real effects of recognizing fair value changes in net income on firms' investment choices. Available at SSRN 3980268.

Tetlock, P. C. 2011. All the news that's fit to reprint: Do investors react to stale information? The Review of Financial Studies 24:1481-1512.

Tetlock, P. C. 2014. Information transmission in finance. Annual Review of Finance and Economics $6: 365-384$. 
Figure 1. Examples of Income Statements After and Before ASU 2016-01

Panel A: Old Republic International Corporation 2018 Earnings Report Excerpt

\begin{tabular}{|c|c|c|c|c|c|c|c|c|c|c|}
\hline \multicolumn{11}{|c|}{ FINANCIAL HIGHLIGHTS (a) } \\
\hline & \multicolumn{5}{|c|}{ Quarters Ended December 31, } & \multicolumn{5}{|c|}{ Years Ended December 31, } \\
\hline & & 2018 & & 2017 & Change & & 2018 & & 2017 & Change \\
\hline \multicolumn{11}{|l|}{ Revenues: } \\
\hline Net premiums and fees earned & $\$$ & $1,448.4$ & $\$$ & $1,442.4$ & $0.4 \%$ & $\$$ & $5,703.9$ & $\$$ & $5,539.7$ & $3.0 \%$ \\
\hline Net investment income & & 110.3 & & 103.7 & 6.3 & & 431.8 & & 409.4 & 5.5 \\
\hline Other income & & 30.4 & & 25.9 & 17.2 & & 121.6 & & 102.2 & 18.9 \\
\hline Total operating revenues & & $1,589.1$ & & $1,572.1$ & 1.1 & & $6,257.4$ & & $6,051.5$ & 3.4 \\
\hline \multicolumn{11}{|l|}{ Investment gains (losses): } \\
\hline Realized from actual transactions & & 3.3 & & 154.0 & & & 58.2 & & 211.6 & \\
\hline Unrealized from changes in fair value of equity securities & & $(311.6)$ & & - & & & $(293.8)$ & & - & \\
\hline Total investment gains (losses) & & $(308.2)$ & & 154.0 & & & $(235.6)$ & & 211.6 & \\
\hline Total revenues & & $1,280.9$ & & $1,726.2$ & & & $6,021.8$ & & $6,263.1$ & \\
\hline \multicolumn{11}{|l|}{ Operating expenses: } \\
\hline Claim costs & & 639.9 & & 534.1 & 19.8 & & $2,460.7$ & & $2,478.8$ & -0.7 \\
\hline Sales and general expenses & & 770.6 & & 822.6 & -6.3 & & $3,080.6$ & & $2,995.7$ & 2.8 \\
\hline Interest and other charges & & 7.8 & & 14.7 & -46.5 & & 42.2 & & 63.0 & -33.0 \\
\hline Total operating expenses & & $1,418.0$ & & $1,371.5$ & $3.4 \%$ & & $5,583.7$ & & $5,537.7$ & $0.8 \%$ \\
\hline Pretax income (loss) & & (137.5) & & 354.7 & & & 438.1 & & 725.4 & \\
\hline Income taxes (credits) & & $(31.0)$ & & 55.0 & & & 67.5 & & 164.8 & \\
\hline Net income (loss) & $\$$ & $(106.5)$ & $\$$ & 299.6 & & $\$$ & 370.5 & $\$$ & 560.5 & \\
\hline
\end{tabular}

Panel B: Old Republic International Corporation 2017 Earnings Report Excerpt

\begin{tabular}{|c|c|c|c|c|c|c|c|c|c|c|}
\hline \multicolumn{11}{|c|}{ Financial Highlights (a) } \\
\hline & \multicolumn{5}{|c|}{ Quarters Ended December 31, } & \multicolumn{5}{|c|}{ Years Ended December 31, } \\
\hline & & 2017 & & 2016 & Change & & 2017 & & 2016 & Change \\
\hline \multicolumn{11}{|l|}{ Operating revenues: } \\
\hline General insurance & $\$$ & 904.0 & $\$$ & 847.6 & $6.7 \%$ & $\$$ & $3,531.6$ & $\$$ & $3,354.7$ & $5.3 \%$ \\
\hline Title insurance & & 626.0 & & 628.9 & -0.5 & & $2,325.0$ & & $2,244.1$ & 3.6 \\
\hline Corporate and other & & 12.4 & & 12.7 & -1.9 & & 50.1 & & 35.4 & 41.3 \\
\hline Subtotal & & $1,542.6$ & & $1,489.3$ & 3.6 & & $5,906.8$ & & $5,634.3$ & 4.8 \\
\hline RFIG run-off business & & 29.5 & & 44.6 & -34.0 & & 144.6 & & 193.2 & -25.2 \\
\hline Total & $\$$ & $1,572.1$ & $\$$ & $1,533.9$ & $2.5 \%$ & $\$$ & $6,051.5$ & $\$$ & $5,827.6$ & $3.8 \%$ \\
\hline \multicolumn{11}{|l|}{ Pretax operating income (loss): } \\
\hline General insurance & $\$$ & 124.1 & $\$$ & 76.8 & $61.5 \%$ & $\$$ & 340.3 & $\$$ & 319.9 & $6.4 \%$ \\
\hline Title insurance & & 64.2 & & 85.6 & -25.0 & & 237.1 & & 210.2 & 12.8 \\
\hline Corporate and other & & $(2.5)$ & & 4.1 & -162.3 & & 9.9 & & 13.0 & -24.1 \\
\hline Subtotal & & 185.8 & & 166.7 & 11.5 & & 587.3 & & 543.3 & 8.1 \\
\hline RFIG run-off business & & 14.8 & & 9.3 & 58.9 & & $(73.5)$ & & 69.8 & -205.4 \\
\hline Total & & 200.6 & & 176.0 & 14.0 & & 513.8 & & 613.1 & -16.2 \\
\hline \multicolumn{11}{|l|}{ Pretax realized investment gains (losses): } \\
\hline From sales & & 154.0 & & 14.7 & $\mathrm{~N} / \mathrm{M}$ & & 211.6 & & 77.8 & 172.0 \\
\hline From impairments & & - & & - & - & & - & & $(4.9)$ & 100.0 \\
\hline Realized investment gains (losses) & & 154.0 & & 14.7 & $\mathrm{~N} / \mathrm{M}$ & & 211.6 & & 72.8 & 190.4 \\
\hline Consolidated pretax income (loss) & & 354.7 & & 190.7 & 85.9 & & 725.4 & & 686.0 & 5.7 \\
\hline Income taxes (credits) & & 55.0 & & 58.7 & -6.3 & & 164.8 & & 219.0 & -24.7 \\
\hline Net income (loss) & $\$$ & 299.6 & $\$$ & 131.9 & $127.0 \%$ & $\$$ & 560.5 & $\$$ & 466.9 & $20.0 \%$ \\
\hline
\end{tabular}


Figure 2. Average Equity Allocation Trend Before and After ASU 2016-01 This figure plots average equity allocation for insurance subsidiaries of public and private companies that operate in the US. Each group's average equity allocation level is scaled by its 2017 value. Equity allocation is the percentage of total investable assets devoted to equity securities. Insurance subsidiaries are considered to be public if their parent companies are listed on at least one US stock exchange. We exclude companies that are listed on a non-US stock exchange. We require that parent companies never change their public-private status during the sample period.

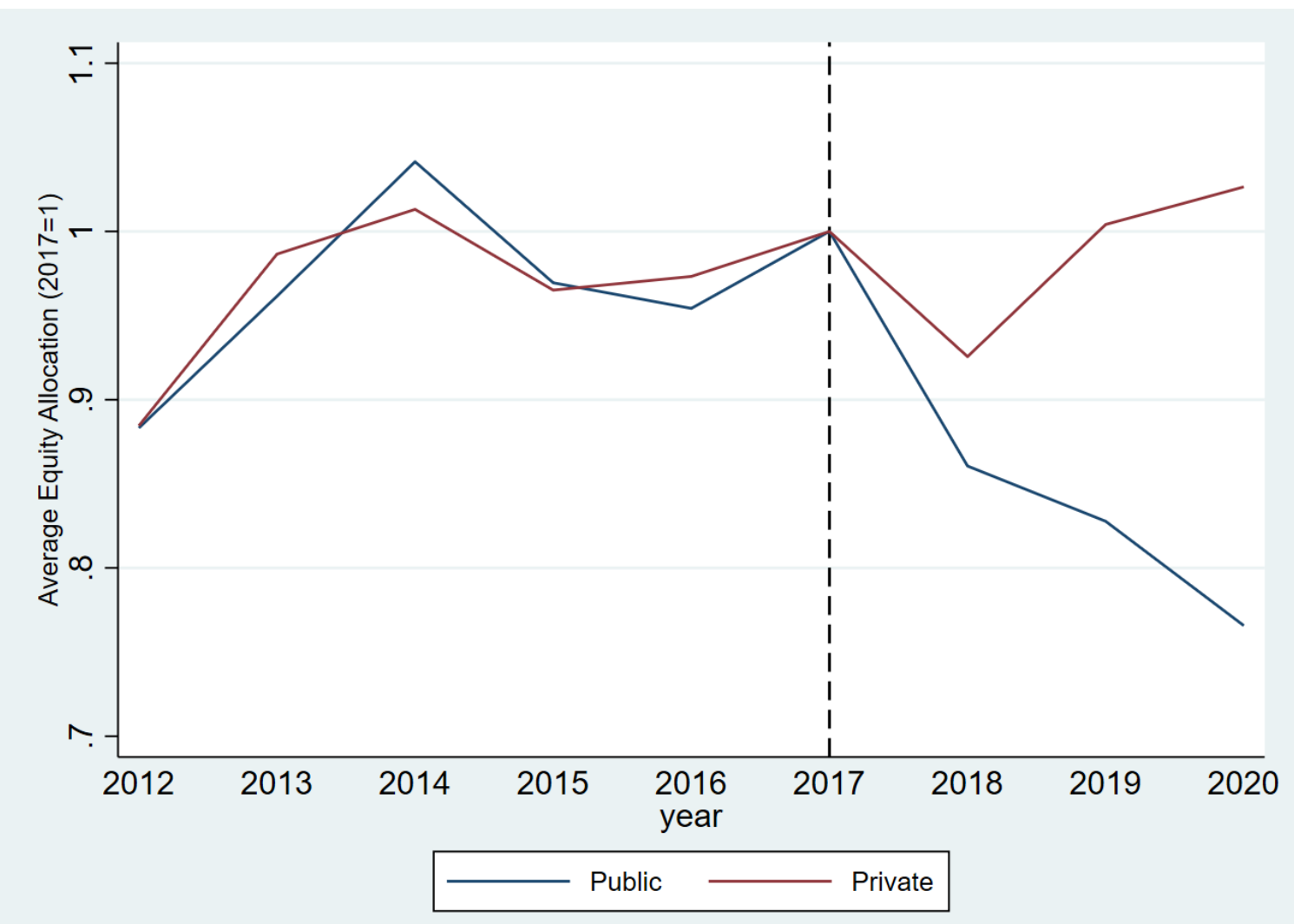


Figure 3. Mean Quarterly EPS Trend This figure plots US-based publicly traded insurers' mean quarterly EPS, including and excluding changes in unrealized gains and losses from equity investments from 2011 to 2020. The vertical line marks 2018Q1, which was the first quarter after ASU 2016-01 was implemented.

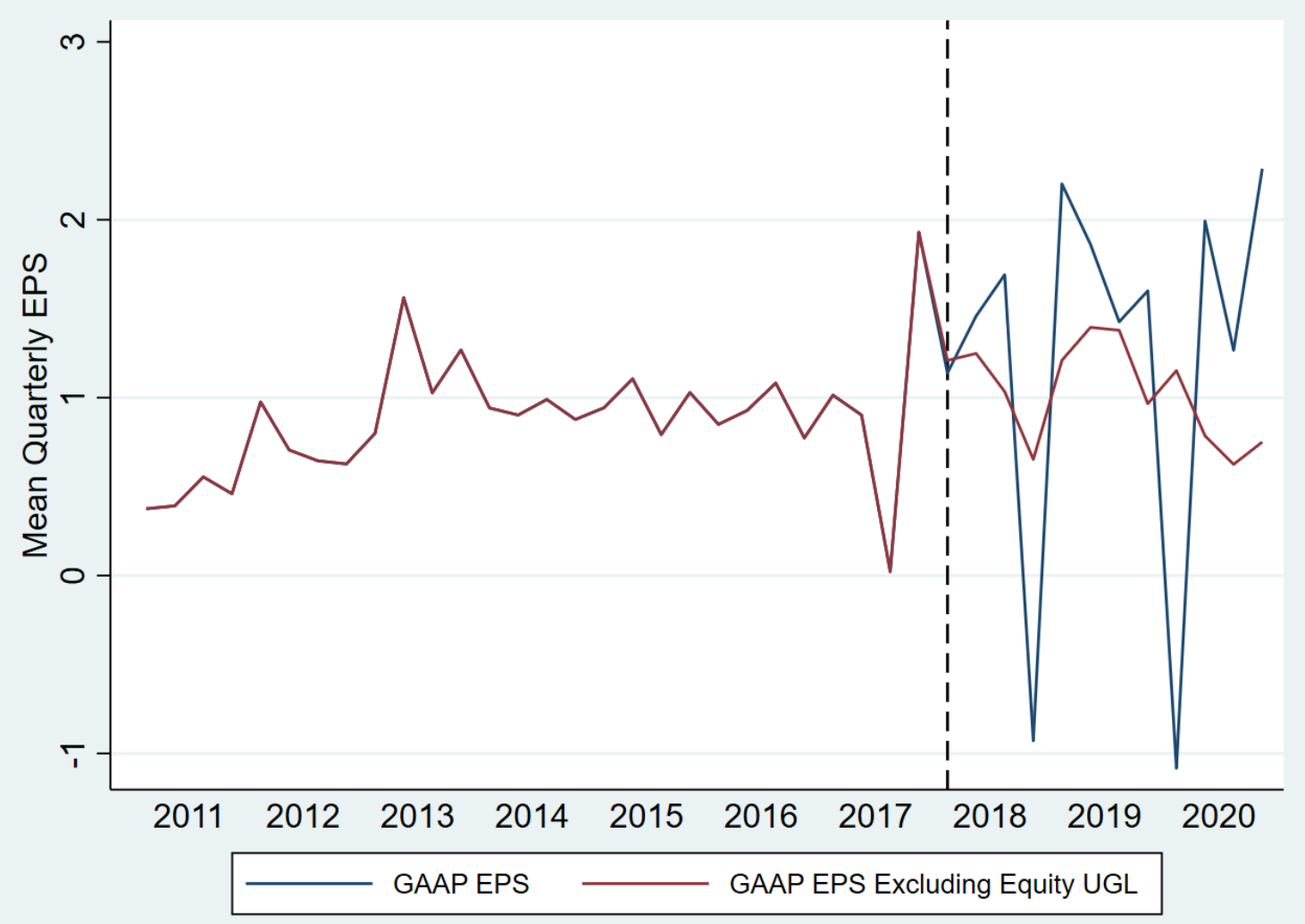


Figure 4. Average Quarterly EPS Volatility Before and After ASU 2016-01 This figure plots average quarterly GAAP earnings per share ( EPS) volatility before and after the implementation of ASU 2016-01. Volatility is defined as the standard deviation of each company's quarterly EPS. The left dot plots average GAAP EPS volatility in the pre-period (2015 to 2017). The middle dot plots average volatility for GAAP EPS excluding changes in equity UGL in the post-period (2018 to 2020). The right dot plots average volatility for GAAP EPS including changes in equity UGL in the post-period (2018 to 2020). EPS excluding changes in equity UGL is defined as GAAP EPS minus changes in unrealized gains and losses from equity investments. $95 \%$ confidence interval bands are shown in red.

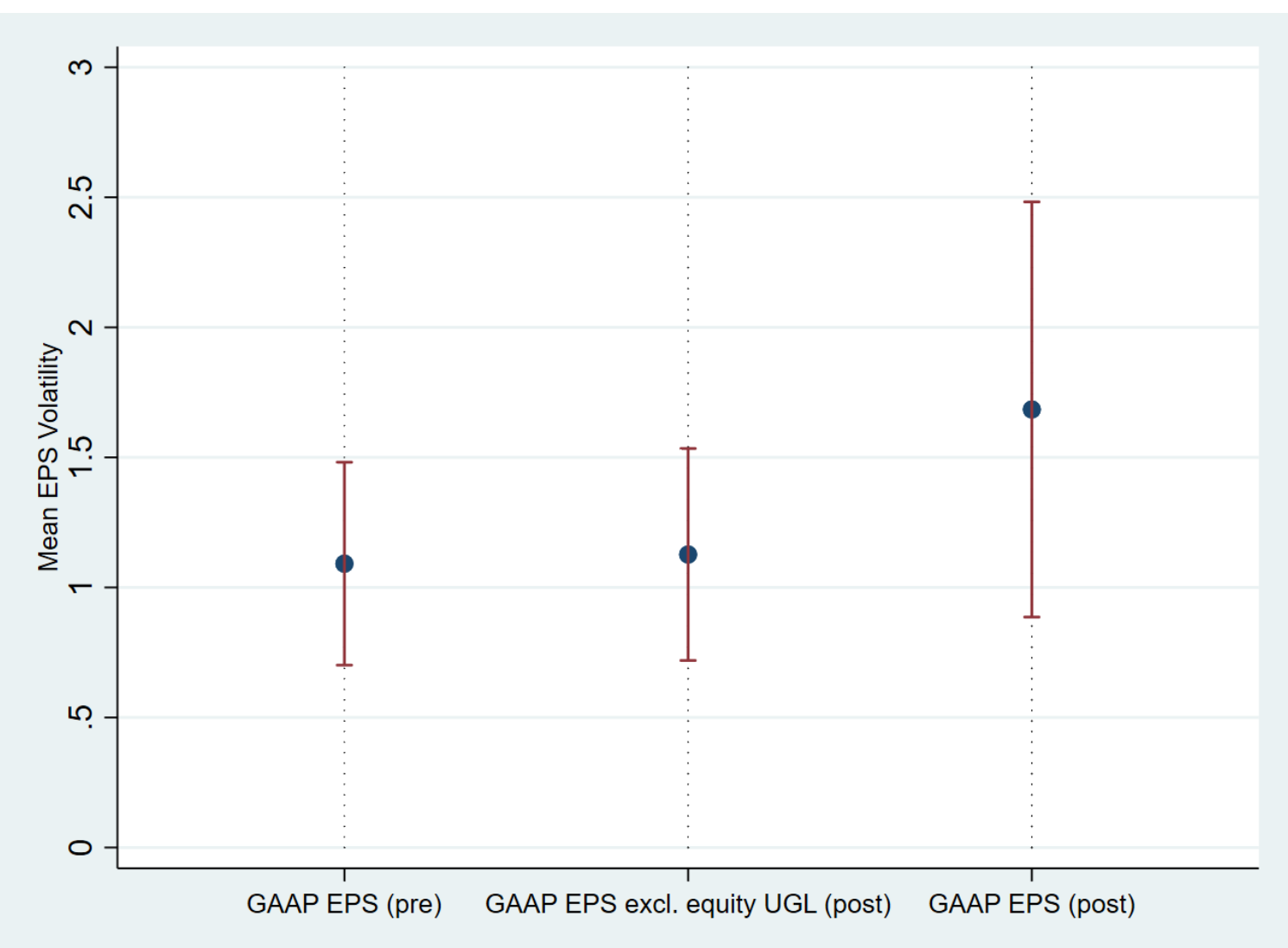


Figure 5. Average Quarterly EPS Persistence Before and After ASU 2016-01 This figure plots average quarterly GAAP earnings per share (EPS) persistence before and after the implementation of ASU 2016-01. Firm-level persistence is defined as the slope coefficient from an OLS regression where next quarter's EPS is regressed onto the current quarter's EPS. To be included in the pre- or post-period sample, each company must have at least ten EPS observations in the sample period. The left dot plots average GAAP EPS persistence in the pre-period (2015 to 2017). The middle dot plots average persistence for GAAP EPS excluding changes in equity UGL in the post-period (2018 to 2020). The right dot plots average persistence for GAAP EPS including changes in equity UGL, in the post period (2018 to 2020). EPS excluding changes in equity UGL is defined as GAAP EPS minus changes in unrealized gains and losses from equity investments. 95\% confidence interval bands are shown in red.

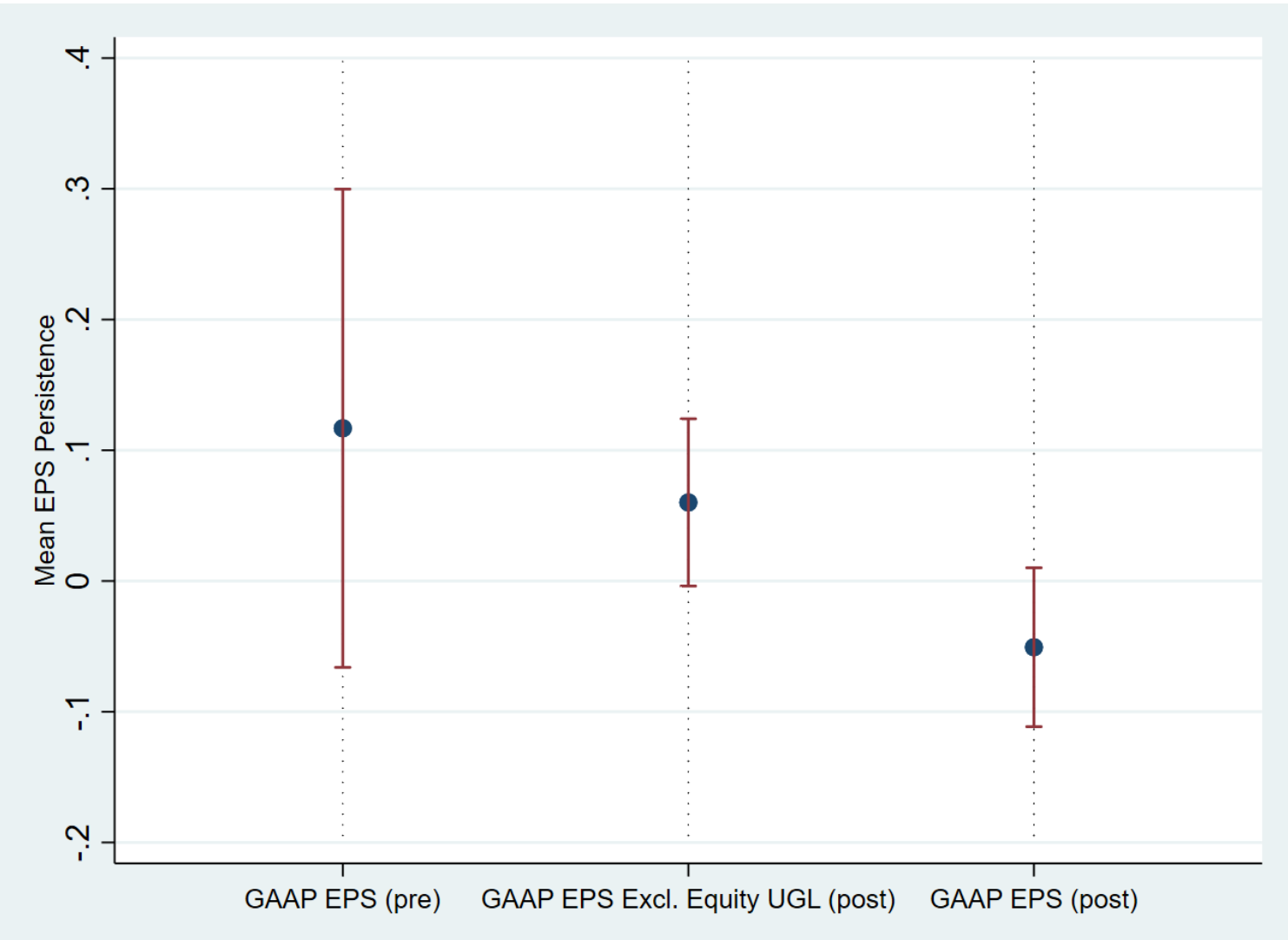


Figure 6. Pre Period High Minus Low Equity UGL Portfolios CAPM CAAR This figure plots the CAPM cumulative average abnormal returns (CAAR) over an event window of $t-30$ to $t+60$, where $t=0$ is the earnings announcement date, of three portfolios that are formed based on equity UGL. This plot uses data from the pre period (2015 to 2017). To form portfolios, we begin by ranking equity UGL across all company-quarters. Equity UGL is calculated as the change in unrealized gains and losses from equity investments per share, scaled by share price from the most recent quarter-end. The top third of the sample forms the top tercile portfolio and so on. Each line plots its respective portfolio's CAPM CAAR from $t-30$ to the relative trading day marked on the $\mathrm{x}$-axis.

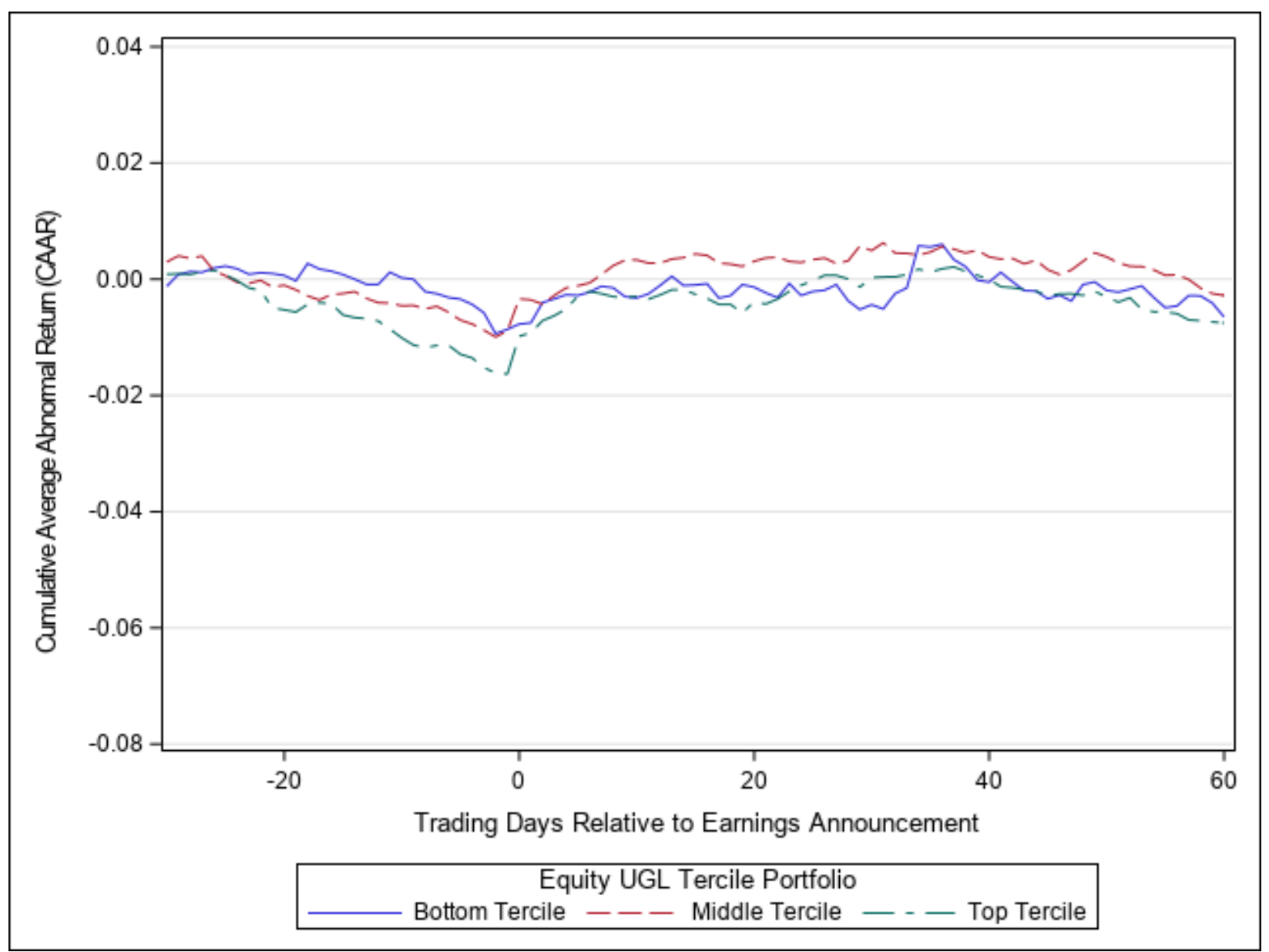


Figure 7. Post-Period High Minus Low Equity UGL Portfolios CAPM CAAR This figure plots the CAPM cumulative average abnormal returns (CAAR) over an event window of $t-30$ to $t$ +60 , where $t=0$ is the earnings announcement date, of three portfolios that are formed based on equity UGL. This plot uses data from the post period (2018 to 2020). To form portfolios, we begin by ranking equity UGL across all company-quarters. Equity UGL is calculated as the change in unrealized gains and losses from equity investments per share, scaled by share price from the most recent quarter-end. The top third of the sample forms the top tercile portfolio and so on. Each line plots its respective portfolio's CAPM CAAR from $t-30$ to the relative trading day marked on the $\mathrm{x}$ axis.

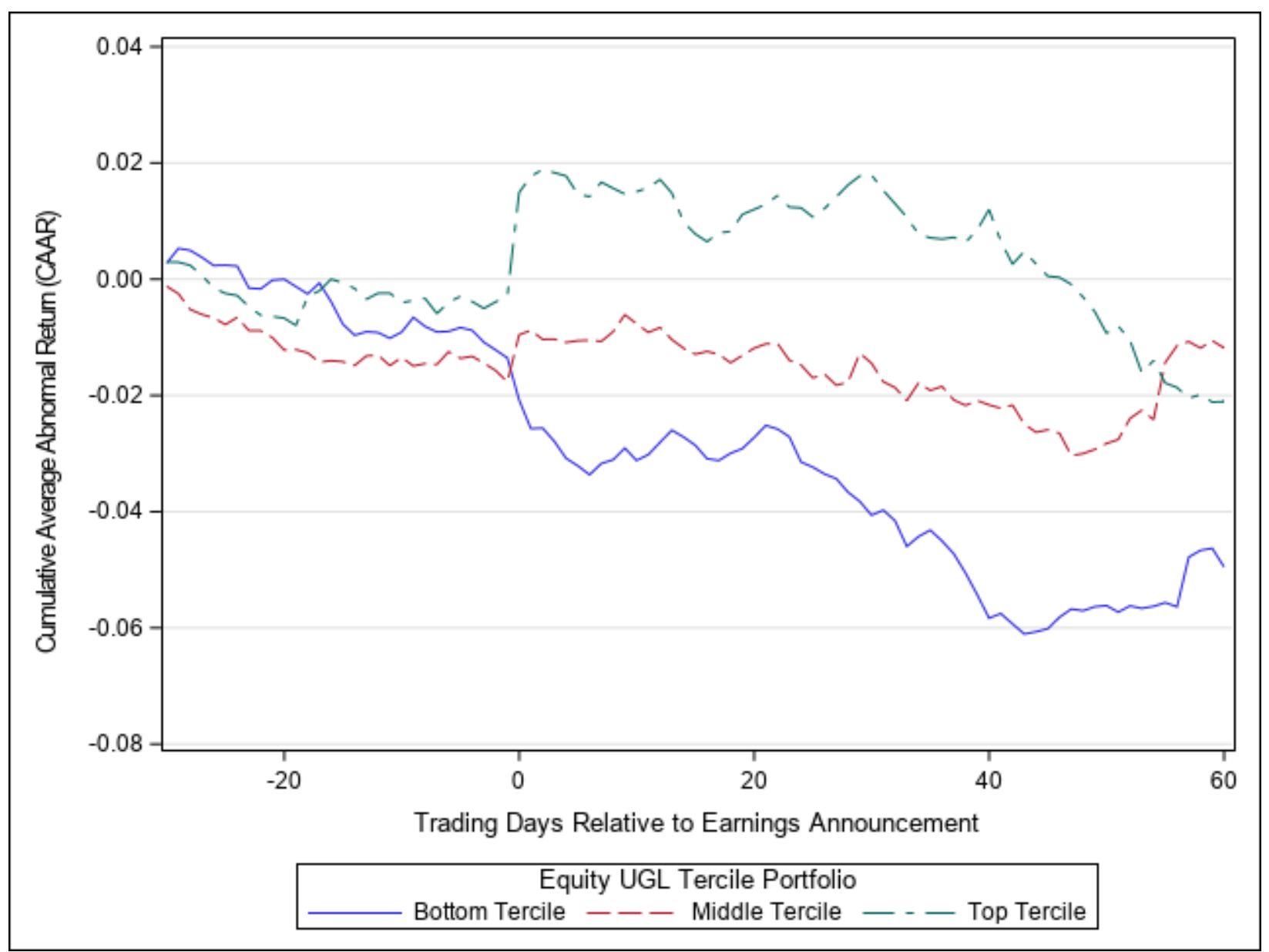


Figure 8. Quarterly Trading Strategy Returns This figure plots quarterly returns from a trading strategy that exploits information on unrealized gains and losses from equity investments. In a given quarter, the trading strategy only includes stocks of US-based public insurance companies with positive equity investments. Consider a certain calendar quarter $q$. If the CRSP value-weighted return for the quarter is positive, the strategy buys these insurance companies' stocks during the following quarter one day before each company's earnings announcement date and holds them until 10 trading days after the earnings announcement date. If the CRSP value-weighted return for the quarter is negative, the strategy sells short these insurance companies' stocks during the following quarter one day before each company's earnings announcement date and closes out the positions 10 trading days after the earnings announcement date. Stocks are weighted according to each insurance company's allocation to equity securities, which is the dollar amount invested in equities divided by total assets, as of the end of quarter $q-1$, such that the weights add up to one. Quarterly returns are calculated as the weighted-average return of these positions. The bars plot returns collected from the following quarter. For example, the 2018Q1 bar plots the returns from trading activity that occurs in 2018Q2.

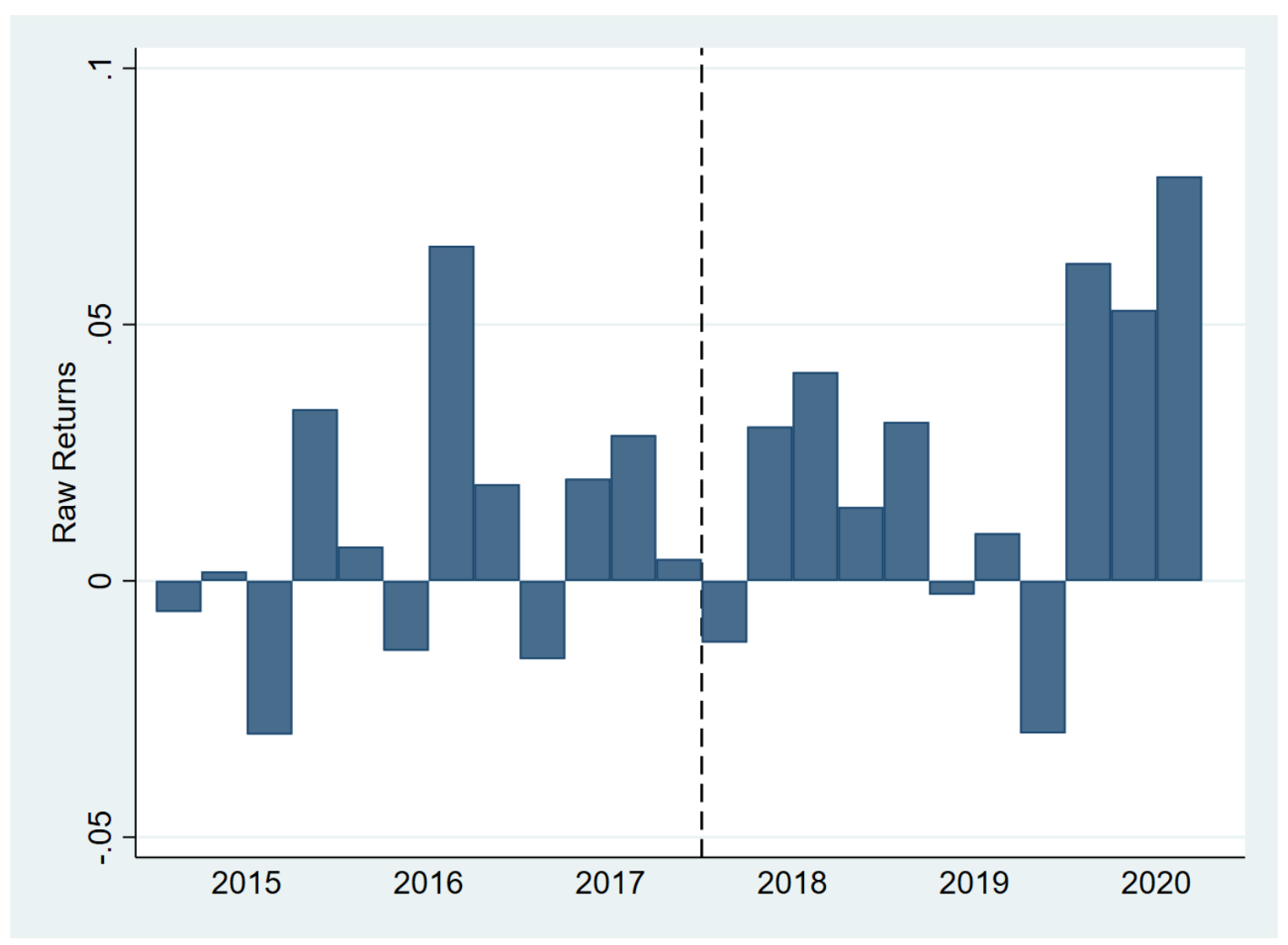


Figure 9. Estimated Impact of ASU 2016-01 on Equity Allocation Before and After 2017 This figure plots OLS regression coefficients from estimating equation 5 . The dependent variable is equity investment allocation, which is the percentage of total investable assets devoted to equity securities. Using 2015 as the reference year, the line graph plots the coefficients on the interaction terms between US Public and year indicator variables, along with each coefficient's $95 \%$ confidence interval. US Public equals 1 for subsidiaries of companies that are traded on at least one US stock exchange. The sample is a balanced panel of insurance subsidiaries of US publicly traded companies and privately-held insurance subsidiaries. We require that parent companies never change their public-private status during the sample period. The accompanying regression table is presented in Table A2.

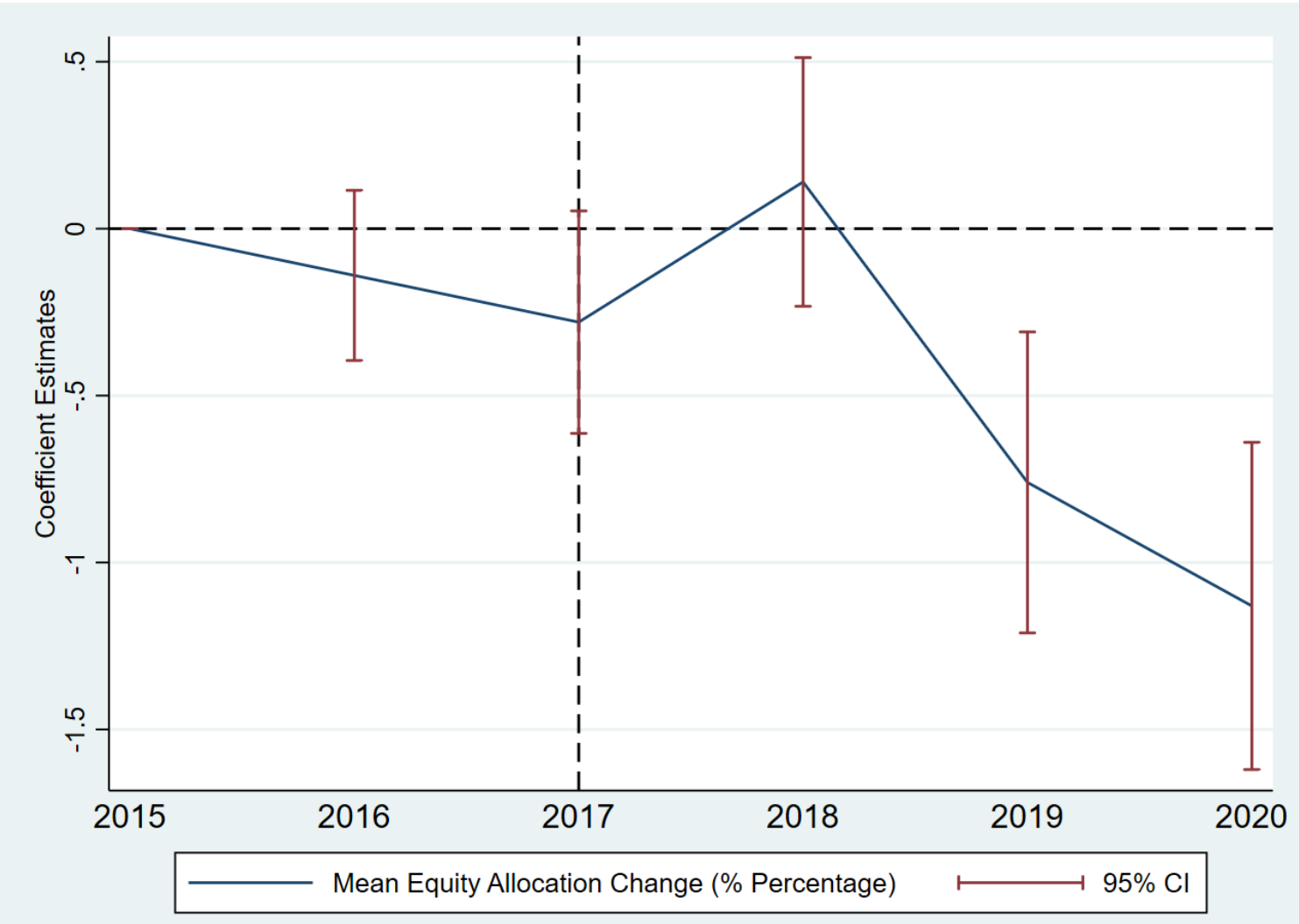


Table 1. Summary Statistics This table presents summary statistics of public insurance companies. Each observation is a company-quarter. UGL stands for unrealized gains and losses. USD values are not inflation-adjusted. Variable definitions are provided in the appendix.

\begin{tabular}{lcccccc}
\hline Variable & $\mathrm{N}$ & Mean & S.D. & 25 th & 50 th & 75 th \\
\hline Property and Casualty & 1,512 & 0.52 & 0.50 & 0.00 & 1.00 & 1.00 \\
Life and Health & 1,512 & 0.27 & 0.44 & 0.00 & 0.00 & 1.00 \\
Multi-line & 1,512 & 0.22 & 0.41 & 0.00 & 0.00 & 0.00 \\
Total Assets (\$ millions) & 1,512 & $50,429.95$ & $126,747.61$ & $2,010.78$ & $8,796.26$ & $31,511.65$ \\
Total Equity Investments (\$ millions) & 1,512 & 772.49 & $1,815.96$ & 5.57 & 120.27 & 435.60 \\
Equity Allocation & 1,512 & 0.04 & 0.05 & 0.00 & 0.01 & 0.06 \\
Leverage & 1,512 & 0.46 & 1.07 & 0.16 & 0.28 & 0.41 \\
Stock Price (\$) & 1,512 & 66.89 & 124.90 & 20.81 & 40.49 & 72.08 \\
Beta & 1,512 & 0.95 & 0.35 & 0.72 & 0.88 & 1.13 \\
Market Capitalization (\$ millions) & 1,512 & $8,451.98$ & $12,809.02$ & 844.80 & $3,135.70$ & $9,249.69$ \\
Market to Book & 1,512 & 1.61 & 3.06 & 0.92 & 1.32 & 1.84 \\
Number of Analysts & 1,512 & 8.04 & 6.07 & 3.00 & 6.00 & 12.00 \\
Core EPS (\$) & 1,512 & 0.83 & 3.01 & 0.30 & 0.69 & 1.21 \\
Equity UGL per share (\$) & 1,512 & 0.09 & 3.71 & 0.00 & 0.00 & 0.07 \\
Fixed Income UGL per share (\$) & 1,512 & 0.18 & 2.57 & -0.19 & 0.01 & 0.37 \\
Core EPS Surprise, Scaled (\%) & 1,512 & -0.17 & 3.76 & -0.16 & 0.07 & 0.31 \\
Equity UGL per Share, Scaled (\%) & 1,512 & 0.03 & 1.33 & 0.00 & 0.00 & 0.19 \\
Fixed Income UGL per Share, Scaled $(\%)$ & 1,512 & 0.44 & 6.49 & -0.55 & 0.02 & 0.93 \\
\hline
\end{tabular}

Table 2. Insurance Subsidiaries Summary Statistics This table presents summary statistics on the full sample of insurance subsidiaries' characteristics. Each observation is a subsidiary-year pair.

\begin{tabular}{lcccccc}
\hline Variables & $\mathrm{N}$ & Mean & S.D. & 25 th & 50 th & 75 th \\
\hline Assets (\$ millions) & 17,952 & $2,327.45$ & $16,778.36$ & 21.56 & 90.79 & 403.34 \\
Cash and Investments (\$ millions) & 17,952 & $1,443.80$ & $10,213.14$ & 15.94 & 65.87 & 291.22 \\
ROE & 17,952 & -0.09 & 27.09 & 0.01 & 0.05 & 0.11 \\
Leverage & 17,952 & 0.49 & 0.26 & 0.31 & 0.52 & 0.68 \\
RBC Ratio & 17,952 & 27.16 & 6.63 & 2.86 & 4.90 & 11.18 \\
Property and Casualty & 17,952 & 0.61 & 0.49 & 0.00 & 1.00 & 1.00 \\
Life and Health & 17,952 & 0.39 & 0.49 & 0.00 & 0.00 & 1.00 \\
Equity Allocation & 17,952 & 8.08 & 14.16 & 0.00 & 0.14 & 11.99 \\
Bond Allocation & 17,952 & 67.38 & 28.90 & 53.04 & 75.97 & 89.79 \\
Real Estate Allocation & 17,952 & 1.00 & 3.92 & 0.00 & 0.00 & 0.00 \\
Mortgage Loan Allocation & 17,952 & 0.81 & 3.70 & 0.00 & 0.00 & 0.00 \\
Alternatives Allocation & 17,952 & 1.60 & 5.45 & 0.00 & 0.00 & 0.79 \\
Contract Loan Allocation & 17,952 & 0.34 & 2.44 & 0.00 & 0.00 & 0.00 \\
Cash Allocation & 17,952 & 20.78 & 27.57 & 3.02 & 8.69 & 26.37 \\
\hline
\end{tabular}


Table 3. CAPM Abnormal Return Reaction This table presents company-quarter panel OLS regression results where CAPM cumulative abnormal returns (CAR) at different time horizons are regressed onto unrealized gains and losses (UGL) from equity investments in the pre and post periods. ST CAPM CAR is the short term cumulative CAPM abnormal return on stock $i$, calculated between $t-1$ and $t+1$ with $t=0$ being the earnings announcement date and $t$ is counted using trading days. MT CAPM CAR is the medium term CAR calculated from $t-1$ to $t+10$. LT CAPM CAR is the long term CAR calculated from $t-1$ to $t+20$. All the independent variables are measured as of the end of that fiscal quarter. Equity UGL is defined as the per share nominal dollar amount of unrealized gains or losses from equity investments recognized during a quarter, scaled by the company's stock price at the end of that quarter. The indicator variable Post equals 1 for observations from 2018Q1 to 2020Q3. All other variables are defined in the appendix. All regressions include company and year-quarter fixed effects. Standard errors are clustered at the company-level and reported in brackets. Asterisks denote statistical significance at the $1 \%\left({ }^{* * *}\right)$, $5 \%(* *)$, and $10 \%(*)$ level.

\begin{tabular}{|c|c|c|c|c|c|c|}
\hline & \multicolumn{2}{|c|}{ ST CAPM CAR } & \multicolumn{2}{|c|}{ MT CAPM CAR } & \multicolumn{2}{|c|}{ LT CAPM CAR } \\
\hline & (1) & $(2)$ & (3) & (4) & (5) & $(6)$ \\
\hline Equity UGL & $\begin{array}{c}-0.62^{*} \\
{[0.35]}\end{array}$ & $\begin{array}{l}-0.51 \\
{[0.37]}\end{array}$ & $\begin{array}{l}-0.99 \\
{[0.79]}\end{array}$ & $\begin{array}{l}-0.80 \\
{[0.82]}\end{array}$ & $\begin{array}{l}-1.52 \\
{[0.97]}\end{array}$ & $\begin{array}{l}-1.32 \\
{[0.96]}\end{array}$ \\
\hline Equity UGL $\times$ Post & $\begin{array}{c}1.49^{* * *} \\
{[0.35]}\end{array}$ & $\begin{array}{c}1.24^{* * *} \\
{[0.37]}\end{array}$ & $\begin{array}{c}2.61^{* * * *} \\
{[0.83]}\end{array}$ & $\begin{array}{c}2.26^{* * *} \\
{[0.84]}\end{array}$ & $\begin{array}{c}3.02^{* * *} \\
{[1.04]}\end{array}$ & $\begin{array}{c}2.60^{* *} \\
{[0.99]}\end{array}$ \\
\hline EPS Surprise & & $\begin{array}{c}1.01^{* * *} \\
{[0.37]}\end{array}$ & & $\begin{array}{c}1.03^{* * *} \\
{[0.39]}\end{array}$ & & $\begin{array}{c}0.96^{* *} \\
{[0.39]}\end{array}$ \\
\hline EPS Surprise $\times$ Post & & $\begin{array}{l}-0.38 \\
{[0.37]}\end{array}$ & & $\begin{array}{l}-0.30 \\
{[0.36]}\end{array}$ & & $\begin{array}{l}-0.34 \\
{[0.34]}\end{array}$ \\
\hline Fixed Income UGL & & $\begin{array}{l}-0.09 \\
{[0.10]}\end{array}$ & & $\begin{array}{l}-0.03 \\
{[0.10]}\end{array}$ & & $\begin{array}{c}0.05 \\
{[0.13]}\end{array}$ \\
\hline Fixed Income UGL $\times$ Post & & $\begin{array}{c}0.04 \\
{[0.14]}\end{array}$ & & $\begin{array}{l}-0.00 \\
{[0.13]}\end{array}$ & & $\begin{array}{l}-0.04 \\
{[0.19]}\end{array}$ \\
\hline RGL & & $\begin{array}{c}0.61 \\
{[0.61]}\end{array}$ & & $\begin{array}{c}0.59 \\
{[0.84]}\end{array}$ & & $\begin{array}{c}1.38 \\
{[1.06]}\end{array}$ \\
\hline RGL $\times$ Post & & $\begin{array}{l}-0.31 \\
{[0.90]}\end{array}$ & & $\begin{array}{c}0.09 \\
{[1.13]}\end{array}$ & & $\begin{array}{l}-0.74 \\
{[1.45]}\end{array}$ \\
\hline Size & & $\begin{array}{c}-0.03^{* * *} \\
{[0.01]}\end{array}$ & & $\begin{array}{c}-0.05^{* * *} \\
{[0.01]}\end{array}$ & & $\begin{array}{c}-0.07^{* * *} \\
{[0.02]}\end{array}$ \\
\hline Leverage & & $\begin{array}{l}-0.01 \\
{[0.01]}\end{array}$ & & $\begin{array}{l}-0.00 \\
{[0.01]}\end{array}$ & & $\begin{array}{l}-0.00 \\
{[0.01]}\end{array}$ \\
\hline Market to Book & & $\begin{array}{c}-0.01^{* *} \\
{[0.00]}\end{array}$ & & $\begin{array}{c}-0.01^{* *} \\
{[0.01]}\end{array}$ & & $\begin{array}{c}-0.02^{* *} \\
{[0.01]}\end{array}$ \\
\hline Beta & & $\begin{array}{c}0.00 \\
{[0.01]}\end{array}$ & & $\begin{array}{c}0.03^{* *} \\
{[0.01]}\end{array}$ & & $\begin{array}{c}0.02 \\
{[0.01]}\end{array}$ \\
\hline Company FE & Y & $\mathrm{Y}$ & $\mathrm{Y}$ & $\mathrm{Y}$ & $\mathrm{Y}$ & $\mathrm{Y}$ \\
\hline Year-Quarter FE & $\mathrm{Y}$ & $\mathrm{Y}$ & $\mathrm{Y}$ & $\mathrm{Y}$ & $\mathrm{Y}$ & $\mathrm{Y}$ \\
\hline Observations & 1,512 & 1,512 & 1,512 & 1,512 & 1,512 & 1,512 \\
\hline R-squared & 0.10 & 0.18 & 0.12 & 0.20 & 0.10 & 0.18 \\
\hline
\end{tabular}


Table 4. Carhart Four-Factor Abnormal Return Reaction This table presents companyquarter panel OLS regression results where Carhart four-factor (C4) cumulative abnormal returns (CAR) at different time horizons are regressed onto unrealized gains and losses (UGL) from equity investments in the pre and post periods. ST C4 CAR is the cumulative $\mathrm{C} 4$ abnormal return on stock $i$ between $t-1$ and $t+1$ with $t=0$ being the earnings announcement date and $t$ is counted using trading days. The time window for MT C4 CAR is $t-1$ to $t+10$. The time window for LT C4 CAR is $t-1$ to $t+20$. All the independent variables are measured as of the end of that fiscal quarter. Equity UGL is defined as the per share nominal dollar amount of unrealized gains or losses from equity investments recognized during a quarter, scaled by the company's stock price at the end of that quarter. Post equals 1 for observations from 2018Q1 to 2020Q3. All regressions include company and year-quarter fixed effects. Standard errors are clustered at the company-level and reported in brackets. Asterisks denote statistical significance at the $1 \%(* * *), 5 \%(* *)$, and $10 \%(*)$ level.

\begin{tabular}{|c|c|c|c|c|c|c|}
\hline & \multicolumn{2}{|c|}{ ST C4 CAR } & \multicolumn{2}{|c|}{ MT C4 CAR } & \multicolumn{2}{|c|}{ LT C4 CAR } \\
\hline & (1) & (2) & (3) & (4) & (5) & (6) \\
\hline Equity UGL & $\begin{array}{l}-0.46 \\
{[0.33]}\end{array}$ & $\begin{array}{l}-0.37 \\
{[0.35]}\end{array}$ & $\begin{array}{l}-0.76 \\
{[0.67]}\end{array}$ & $\begin{array}{l}-0.60 \\
{[0.69]}\end{array}$ & $\begin{array}{l}-1.37 \\
{[0.96]}\end{array}$ & $\begin{array}{l}-1.21 \\
{[0.94]}\end{array}$ \\
\hline Equity UGL $\times$ Post & $\begin{array}{c}1.37^{* * *} \\
{[0.39]}\end{array}$ & $\begin{array}{c}1.13^{* * *} \\
{[0.38]}\end{array}$ & $\begin{array}{c}2.43^{* * *} \\
{[0.77]}\end{array}$ & $\begin{array}{c}2.15^{* * *} \\
{[0.76]}\end{array}$ & $\begin{array}{l}2.72^{* *} \\
{[1.09]}\end{array}$ & $\begin{array}{c}2.42^{* *} \\
{[1.06]}\end{array}$ \\
\hline EPS Surprise & & $\begin{array}{c}1.05^{* * *} \\
{[0.36]}\end{array}$ & & $\begin{array}{l}1.05^{* *} \\
{[0.40]}\end{array}$ & & $\begin{array}{l}1.07^{* *} \\
{[0.44]}\end{array}$ \\
\hline EPS Surprise $\times$ Post & & $\begin{array}{l}-0.43 \\
{[0.37]}\end{array}$ & & $\begin{array}{l}-0.37 \\
{[0.40]}\end{array}$ & & $\begin{array}{l}-0.54 \\
{[0.43]}\end{array}$ \\
\hline Fixed Income UGL & & $\begin{array}{l}-0.13 \\
{[0.10]}\end{array}$ & & $\begin{array}{l}-0.08 \\
{[0.10]}\end{array}$ & & $\begin{array}{l}-0.03 \\
{[0.13]}\end{array}$ \\
\hline Fixed Income UGL $\times$ Post & & $\begin{array}{l}0.05 \\
{[0.13]}\end{array}$ & & $\begin{array}{c}0.08 \\
{[0.14]}\end{array}$ & & $\begin{array}{c}0.10 \\
{[0.18]}\end{array}$ \\
\hline RGL & & $\begin{array}{c}0.67 \\
{[0.58]}\end{array}$ & & $\begin{array}{c}0.70 \\
{[0.77]}\end{array}$ & & $\begin{array}{c}0.94 \\
{[0.94]}\end{array}$ \\
\hline RGL $\times$ Post & & $\begin{array}{l}-0.18 \\
{[0.76]}\end{array}$ & & $\begin{array}{c}0.25 \\
{[0.95]}\end{array}$ & & $\begin{array}{c}0.13 \\
{[1.29]}\end{array}$ \\
\hline Size & & $\begin{array}{c}-0.03^{* * *} \\
{[0.01]}\end{array}$ & & $\begin{array}{c}-0.04^{* * *} \\
{[0.01]}\end{array}$ & & $\begin{array}{c}-0.05^{* * *} \\
{[0.01]}\end{array}$ \\
\hline Leverage & & $\begin{array}{l}-0.01 \\
{[0.01]}\end{array}$ & & $\begin{array}{l}-0.00 \\
{[0.01]}\end{array}$ & & $\begin{array}{c}0.00 \\
{[0.01]}\end{array}$ \\
\hline Market to Book & & $\begin{array}{c}-0.01^{* *} \\
{[0.00]}\end{array}$ & & $\begin{array}{c}-0.01^{* *} \\
{[0.01]}\end{array}$ & & $\begin{array}{c}-0.02^{* * *} \\
{[0.01]}\end{array}$ \\
\hline Beta & & $\begin{array}{c}0.00 \\
{[0.01]}\end{array}$ & & $\begin{array}{c}0.02 \\
{[0.01]}\end{array}$ & & $\begin{array}{c}0.01 \\
{[0.02]}\end{array}$ \\
\hline Company FE & Y & Y & Y & $\mathrm{Y}$ & $\mathrm{Y}$ & Y \\
\hline Year-Quarter FE & Y & Y & Y & $\mathrm{Y}$ & Y & $\mathrm{Y}$ \\
\hline Observations & 1,512 & 1,512 & 1,512 & 1,512 & 1,512 & 1,512 \\
\hline R-squared & 0.09 & 0.18 & 0.10 & 0.18 & 0.10 & 0.17 \\
\hline
\end{tabular}


Table 5. Analyst Coverage and Return Reaction This table presents company-quarter panel OLS regression results where CAPM and Carhart four-factor (C4) cumulative abnormal returns (CAR) calculated over different time horizons are regressed onto unrealized gains and losses from equity investments, Equity UGL. Post equals 1 for 2018Q1 to 2020Q3. High Cov equals 1 for insurance companies that have higher-than-median average number of analysts covering them between 2015 and 2020. Control variables include EPS Surprise, Fixed Income UGL, Log Market Capitalization, Leverage, Market to Book, Beta, and their interaction terms with Post. All regressions include company and year-quarter fixed effects. Standard errors are clustered at the company-level and reported in brackets. Asterisks denote statistical significance at the $1 \%(* * *)$, $5 \%(* *)$, and $10 \%(*)$ level. Refer to the appendix for the full regression output.

\begin{tabular}{lcccccc}
\hline & ST CAPM & MT CAPM & LT CAPM & ST C4 & MT C4 & LT C4 \\
\hline & $(1)$ & $(2)$ & $(3)$ & $(4)$ & $(5)$ & $(6)$ \\
\hline & & & & & & \\
Equity UGL & -0.68 & -1.14 & $-1.90^{*}$ & -0.49 & -0.85 & -1.58 \\
& {$[0.43]$} & {$[0.91]$} & {$[1.02]$} & {$[0.42]$} & {$[0.77]$} & {$[1.01]$} \\
Equity UGL $\times$ Post & $1.37^{* * *}$ & $2.63^{* * *}$ & $3.35^{* * *}$ & $1.27^{* * *}$ & $2.52^{* * *}$ & $3.04^{* *}$ \\
& {$[0.44]$} & {$[0.94]$} & {$[1.07]$} & {$[0.47]$} & {$[0.87]$} & {$[1.16]$} \\
Post $\times$ High Cov & 0.01 & 0.02 & $0.04^{* *}$ & $0.02^{*}$ & 0.02 & 0.02 \\
& {$[0.01]$} & {$[0.01]$} & {$[0.02]$} & {$[0.01]$} & {$[0.01]$} & {$[0.02]$} \\
Equity UGL $\times$ High Cov & 1.01 & 1.34 & $2.26^{*}$ & 0.69 & 1.06 & 1.65 \\
& {$[0.64]$} & {$[0.94]$} & {$[1.14]$} & {$[0.60]$} & {$[0.88]$} & {$[1.23]$} \\
Equity UGL $\times$ Post $\times$ High Cov & -0.85 & $-1.50^{*}$ & $-3.00^{* * *}$ & -0.82 & $-1.77^{* *}$ & $-2.88^{* *}$ \\
& {$[0.69]$} & {$[0.87]$} & {$[1.09]$} & {$[0.68]$} & {$[0.87]$} & {$[1.16]$} \\
Controls & & & & & & \\
Controls $\times$ Post & $\mathrm{Y}$ & $\mathrm{Y}$ & $\mathrm{Y}$ & $\mathrm{Y}$ & $\mathrm{Y}$ & $\mathrm{Y}$ \\
Company FE & $\mathrm{Y}$ & $\mathrm{Y}$ & $\mathrm{Y}$ & $\mathrm{Y}$ & $\mathrm{Y}$ & $\mathrm{Y}$ \\
Year-Quarter FE & $\mathrm{Y}$ & $\mathrm{Y}$ & $\mathrm{Y}$ & $\mathrm{Y}$ & $\mathrm{Y}$ & $\mathrm{Y}$ \\
& $\mathrm{Y}$ & $\mathrm{Y}$ & $\mathrm{Y}$ & $\mathrm{Y}$ & $\mathrm{Y}$ & $\mathrm{Y}$ \\
\hline Observations & & & & & & \\
R-squared & 1,512 & 1,512 & 1,512 & 1,512 & 1,512 & 1,512 \\
\hline
\end{tabular}


Table 6. Equity Investment Allocation Regression Results - Full Sample This table presents panel OLS regression results for variants of equation 3. The sample is a balanced panel of insurance subsidiaries of publicly traded companies and privately held insurance subsidiaries. Subsidiaries of parent companies that are listed on a non-US stock exchange are excluded. The dependent variable is equity investment allocation, which is the percentage of the insurer's investment portfolio that is devoted to equity securities times 100. US Public is an indicator variable that equals 1 if the subsidiary belongs to a parent company that is listed on a US stock exchange. Post equals 1 for observations in years 2018, 2019, and 2020. Other covariates are lagged by one year. Columns 1 and 2 present results for all insurance subsidiaries. Columns 3 and 4 present results by insurance business type. P\&C stands for property and casualty insurance companies. L\&H stands for life and health insurance companies. All regressions include subsidiary and year fixed effects. Standard errors are clustered at the subsidiary-level and reported in brackets. Asterisks denote statistical significance at the 1\% (***), 5\% (**), and 10\% (*) level. Refer to the appendix for the full regression output and more details on variable definitions.

\begin{tabular}{lcccc}
\hline & $(1)$ & $(2)$ & $(3)$ & $(4)$ \\
\hline & & & & \\
US Public $\times$ Post & $-0.47^{* * *}$ & $-0.44^{* * *}$ & $-0.53^{* *}$ & -0.32 \\
& {$[0.16]$} & {$[0.16]$} & {$[0.22]$} & {$[0.22]$} \\
Log Total Assets & & $0.41^{*}$ & 0.23 & $0.60^{* * *}$ \\
& & {$[0.24]$} & {$[0.48]$} & {$[0.22]$} \\
ROE & & 0.47 & 0.77 & 0.40 \\
& & {$[0.29]$} & {$[0.57]$} & {$[0.35]$} \\
Leverage & $-2.57^{* * *}$ & $-3.38^{* * *}$ & $-1.84^{* *}$ \\
& & {$[0.67]$} & {$[1.02]$} & {$[0.89]$} \\
RBC & & $-0.01^{* * *}$ & $-0.01^{* * *}$ & -0.00 \\
& & {$[0.00]$} & {$[0.00]$} & {$[0.00]$} \\
Sample & All & All & P\&C & L\&H \\
Subsidiary FE & Y & Y & Y & Y \\
Year FE & $\mathrm{Y}$ & Y & Y & $\mathrm{Y}$ \\
& & & & \\
\hline Observations & 17,952 & 17,952 & 10,974 & 6,978 \\
R-squared & 0.92 & 0.92 & 0.93 & 0.89 \\
\hline
\end{tabular}


Table 7. Propensity Score Matched Sample 2015 Characteristics This table presents average values of insurance subsidiaries' characteristics at the end of 2015. Each insurance subsidiary that is owned by a publicly traded company is matched with a privately owned insurance subsidiary using the propensity score matching procedure described in Section 6.6. The fourth column reports the mean difference of each variable across the two groups and the last column reports the p-value from difference of means t-tests.

\begin{tabular}{lcccc}
\hline Variables & Public & Private & Difference & p-value \\
\hline Assets (\$ millions) & $3,768.13$ & $3,099.97$ & 668.16 & 0.51 \\
Cash and Investments (\$ millions) & $2,186.32$ & $2,100.13$ & 86.19 & 0.89 \\
Leverage & 0.51 & 0.49 & 0.02 & 0.13 \\
RBC Ratio & 29.25 & 30.87 & -1.61 & 0.65 \\
ROE & 0.30 & 0.35 & -0.05 & 0.91 \\
Equity Allocation & 2.54 & 9.77 & -7.23 & $<.01$ \\
Bond Allocation & 74.31 & 67.94 & 6.37 & $<.01$ \\
Real Estate Allocation & 0.36 & 1.42 & -1.06 & $<.01$ \\
Mortgage Loan Allocation & 0.79 & 0.89 & -0.10 & 0.57 \\
Alternatives Allocation & 1.27 & 1.70 & -0.43 & 0.02 \\
Contract Loan Allocation & 0.32 & 0.47 & -0.15 & 0.29 \\
Cash Allocation & 20.41 & 18.01 & 2.40 & 0.08 \\
\hline
\end{tabular}


Table 8. Equity Investment Allocation Regression Results - Propensity Score Matched Sample This table presents panel OLS regression results for variants of equation 3 . The sample is a sample of insurance subsidiaries of publicly traded companies and their propensity-matched privately held insurance subsidiaries. Subsidiaries of parent companies that are listed on a non-US stock exchange are excluded. The dependent variable is equity investment allocation, which is the percentage of the insurer's investment portfolio that is devoted to equity securities times 100 . US Public is an indicator variable that equals 1 if the subsidiary belongs to a parent company that is listed on a US stock exchange. Post equals 1 for observations in years 2018, 2019, and 2020. Other covariates are lagged by one year. Columns 1 and 2 present results for all insurance subsidiaries. Columns 3 and 4 present results by insurance business type. P\&C stands for property and casualty insurance companies. L\&H stands for life and health insurance companies. All regressions include subsidiary and year fixed effects. Standard errors are clustered at the subsidiary-level and reported in brackets. Asterisks denote statistical significance at the 1\% (***), 5\% (**), and 10\% (*) level. Refer to the appendix for the full regression output and more details on variable definitions.

\begin{tabular}{lcccc}
\hline & $(1)$ & $(2)$ & $(3)$ & $(4)$ \\
\hline & & & & \\
US Public $\times$ Post & $-0.41^{* *}$ & $-0.38^{*}$ & $-0.64^{* *}$ & -0.05 \\
& {$[0.20]$} & {$[0.20]$} & {$[0.26]$} & {$[0.30]$} \\
Log Total Assets & & $0.60^{* * *}$ & $0.65^{* *}$ & $0.65^{* * *}$ \\
& & {$[0.16]$} & {$[0.28]$} & {$[0.20]$} \\
ROE & & 0.15 & 0.50 & 0.09 \\
& & {$[0.28]$} & {$[0.79]$} & {$[0.30]$} \\
Leverage & & $-2.18^{* * *}$ & $-1.97^{* *}$ & $-2.38^{* * *}$ \\
& & {$[0.66]$} & {$[0.92]$} & {$[0.87]$} \\
RBC & & $-0.01^{* * *}$ & $-0.01^{* * *}$ & -0.00 \\
& & {$[0.00]$} & {$[0.00]$} & {$[0.00]$} \\
Sample & & & \\
Subsidiary FE & All & All & P\&C & L\&H \\
Year FE & $\mathrm{Y}$ & $\mathrm{Y}$ & $\mathrm{Y}$ & $\mathrm{Y}$ \\
& & & & $\mathrm{Y}$ \\
\hline Observations & 9,648 & 9,648 & 5,328 & 4,320 \\
R-squared & 0.94 & 0.94 & 0.95 & 0.90 \\
\hline
\end{tabular}




\section{A Appendix}

\section{A.1 Variable Definitions}

\begin{tabular}{|c|c|}
\hline Variable & Definition \\
\hline Size & Log of market capitalization at the end of a fiscal quarter. \\
\hline Leverage & $\begin{array}{l}\text { Total liabilities divided by total shareholders' equity at the end } \\
\text { of a fiscal quarter. }\end{array}$ \\
\hline Market to Book Ratio & $\begin{array}{l}\text { Market capitalization divided by total shareholders' equity at } \\
\text { the end of a fiscal quarter. }\end{array}$ \\
\hline Beta & $\begin{array}{l}\text { Coefficient from regressing daily stock returns on daily CRSP } \\
\text { value-weighted returns, over a period of one year, leading up to } \\
\text { the earnings announcement date. }\end{array}$ \\
\hline Equity UGL & $\begin{array}{l}\text { Changes in unrealized gains and losses that a firm recognizes on } \\
\text { its equity securities investments during a fiscal quarter, divided } \\
\text { by the firm's total shares outstanding, and scaled by its quarter- } \\
\text { end stock price. }\end{array}$ \\
\hline Fixed Income UGL & $\begin{array}{l}\text { Changes in unrealized gains and losses that a firm recognizes on } \\
\text { its fixed income securities investments during a fiscal quarter, } \\
\text { divided by the firm's total shares outstanding, and scaled by its } \\
\text { quarter-end stock price. }\end{array}$ \\
\hline RGL & $\begin{array}{l}\text { Realized capital gains and losses that a firm recognized on its in- } \\
\text { vestments in securities during a fiscal quarter. This RGL amount } \\
\text { is divided by the firm's total shares outstanding and scaled by } \\
\text { its quarter-end stock price. }\end{array}$ \\
\hline EPS Surprise & $\begin{array}{l}\text { Firm's I/B/E/S core EPS minus median analyst estimate of core } \\
\text { EPS. The difference is scaled by quarter-end stock price. }\end{array}$ \\
\hline High Cov & $\begin{array}{l}\text { Equals } 1 \text { for firms that have above-median average analyst cov- } \\
\text { erage during the } 2015-2020 \text { sample period. }\end{array}$ \\
\hline $\mathrm{ROE}$ & $\begin{array}{l}\text { Net income divided by the sum of year-end total capital and } \\
\text { surplus. }\end{array}$ \\
\hline RBC Ratio & $\begin{array}{l}\text { Risk-based capital ratio equals total adjusted capital divided by } \\
\text { two times the required risk-based capital at year-end. }\end{array}$ \\
\hline Asset Class Allocation & $\begin{array}{l}\text { Dollar amount invested in a given asset class divided by total } \\
\text { dollar amount in investment portfolio. }\end{array}$ \\
\hline Model CAR & $\begin{array}{l}\text { Model-adjusted cumulative abnormal return. Over a certain } \\
\text { event window, the difference between stock } i \text { 's return and its } \\
\text { model-predicted return, calculated using Kai Chen's SAS macro } \\
\text { for event study. http://kaichen. work } / ? \mathrm{p}=418 \text {. Factor loadings } \\
\text { are estimated using returns data from dates } t-150 \text { to } t-20 \text {. }\end{array}$ \\
\hline
\end{tabular}




\section{A.2 Equity UGL Calculation Example}

In this section, we explain our calculation of changes in equity UGL in the pre period. The addback of capital gains and subtraction of OTTI are important because we would like to capture changes in equity UGL that come from fluctuations in stock prices, which is consistent with how changes in equity UGL are reflected in net income in the post-ASU 2016-01 period. Consider the following example. Suppose that at the end of 2014Q4, company $i$ holds two stocks, A and B. Each stock has an equity UGL of $\$ 100$ or, in other words, an unrealized gain position of $\$ 100$. Between 2014Q4 and 2015Q1, the prices of stocks A and B do not change and, right before the company closes its books for 2015Q1, company $i$ liquidates its position in stock B and realizes a gain of $\$ 100$. The raw change in equity UGL would be $\$ 0-\$ 100=-\$ 100$, which is incorrect. Adding back realized gains from stock B would make the equity UGL equal to $\$ 0$, which reflects the true change in stock prices during 2015Q1. Suppose that, instead, stock B had an unrealized loss position of $-\$ 100$ at the beginning of the quarter, and the company recognizes an OTTI on this stock during the quarter, leading to the removal of the unrealized loss position and recognition of an OTTI loss in net income. The raw change in equity UGL in this case would be $\$ 100$, which again does not reflect changes in stock prices. To deal with this scenario, we subtract the OTTI value from our calculation.

To provide a real-life example, in its $10-\mathrm{Q}$ for the quarter that ended 3/31/2015, Prudential Financial reported, in their investments section, unrealized gains and losses on equity securities of $\$ 3,227$ million and $\$ 66$ million, respectively, compared to $\$ 3,023$ million and $\$ 83$ million as of $12 / 31 / 2014$. We first take the quarterly change in the net unrealized gain/loss position, which equals (3227-66)-(3023-83) $=\$ 221$ million. Then we add back net capital gains on sales of equity securities of $\$ 127$ million that ocurred during the quarter and also subtract $\$ 6$ million of impairments recognized on equity securities that quarter. The resulting $\$ 342$ million represents Prudential's change in equity UGL for the quarter ending 3/31/2015, after adjusting for capital gains and OTTI. 
Figure A1. High Minus Low Equity UGL Portfolios CAPM CAAR - Quarterly Sort This figure plots CAPM c umulative a verage a bnormal returns (CAAR) of three portfolios, formed each quarter based on equity UGL, over an event window of $t-30$ to $t+60$, where $t=0$ is the earnings announcement date, for the pre and post periods. The top third of the sample forms the top tercile portfolio and so on. Each line plots the respective portfolio's CAPM CAAR from $t-30$ to the relative trading day marked on the x-axis.

\section{Panel A: Pre-Period (2015-2017)}

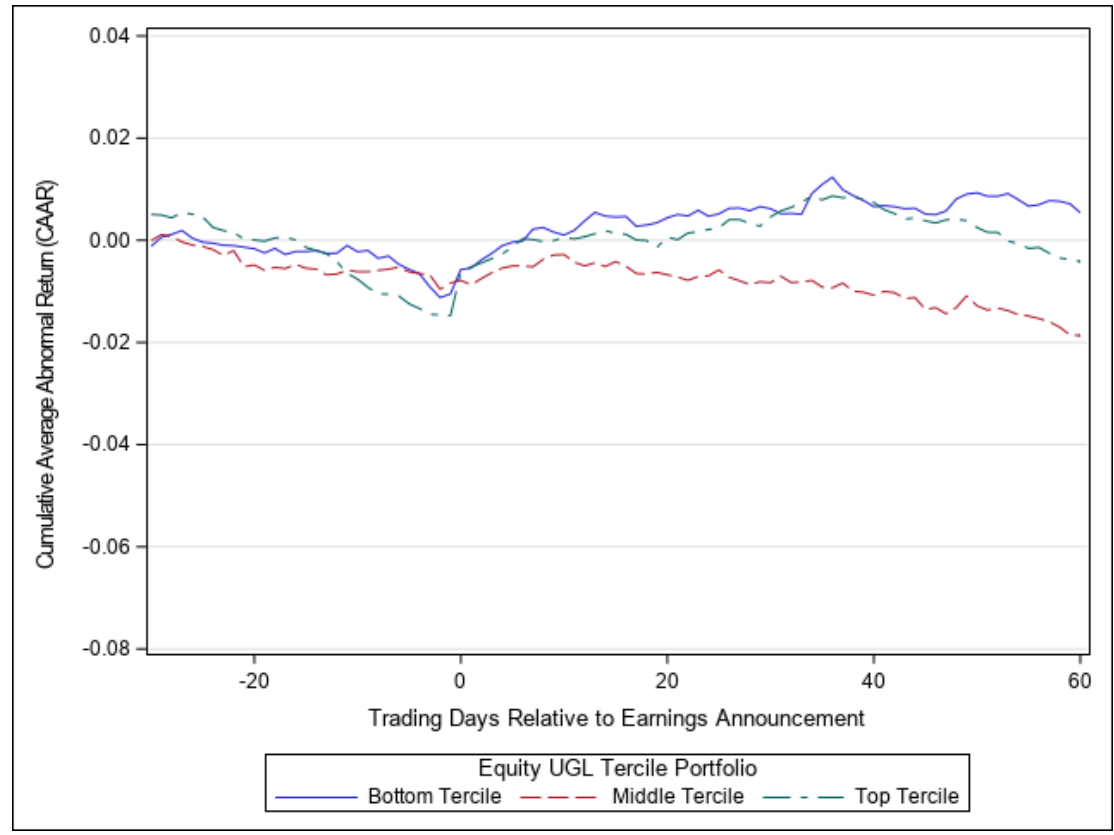

Panel B: Post-Period (2018-2020)

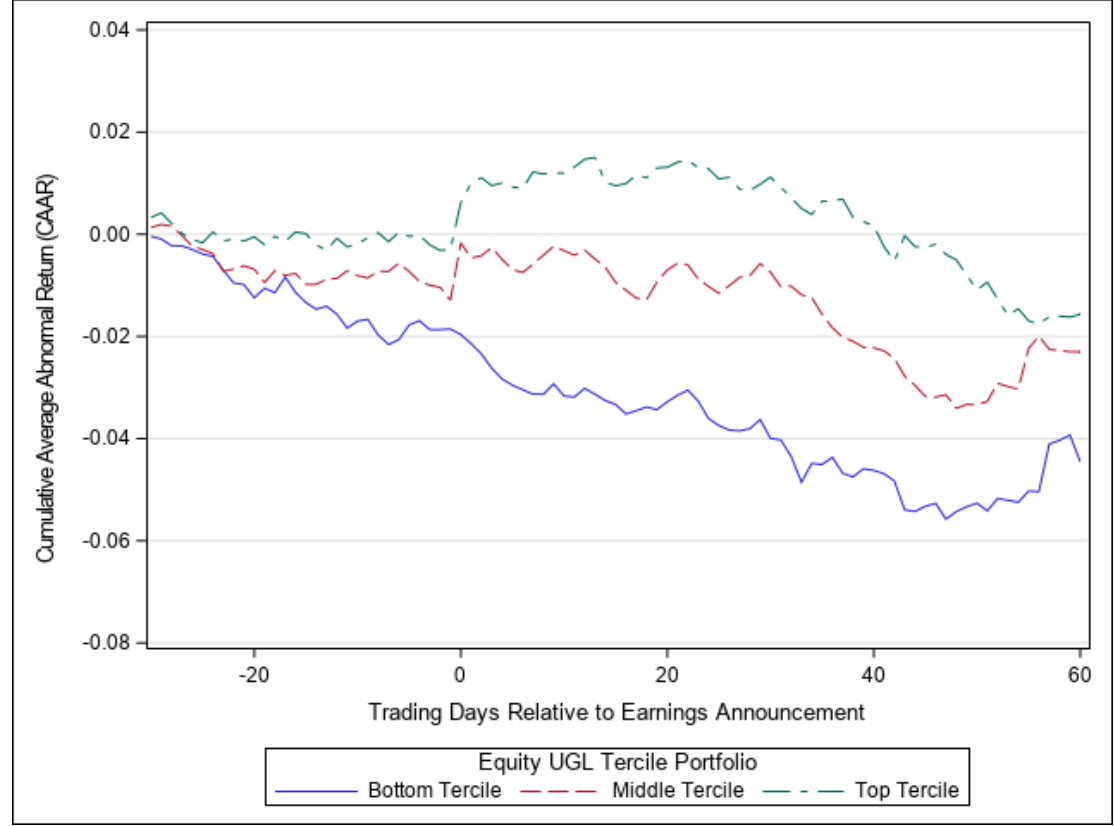


Table A1. Analyst Coverage and Return Reaction - Full Regression Output

\begin{tabular}{|c|c|c|c|c|c|c|}
\hline & ST CAPM & MT CAPM & LT CAPM & ST C4 & MT C4 & LT C4 \\
\hline & (1) & (2) & (3) & (4) & (5) & (6) \\
\hline Equity UGL & $\begin{array}{l}-0.68 \\
{[0.43]}\end{array}$ & $\begin{array}{l}-1.14 \\
{[0.91]}\end{array}$ & $\begin{array}{c}-1.90^{*} \\
{[1.02]}\end{array}$ & $\begin{array}{l}-0.49 \\
{[0.42]}\end{array}$ & $\begin{array}{l}-0.85 \\
{[0.77]}\end{array}$ & $\begin{array}{l}-1.58 \\
{[1.01]}\end{array}$ \\
\hline Equity UGL $\times$ Post & $\begin{array}{c}1.37^{* * *} \\
{[0.44]}\end{array}$ & $\begin{array}{c}2.63^{* * *} \\
{[0.94]}\end{array}$ & $\begin{array}{c}3.35^{* * *} \\
{[1.07]}\end{array}$ & $\begin{array}{c}1.27^{* * *} \\
{[0.47]}\end{array}$ & $\begin{array}{c}2.52^{* * *} \\
{[0.87]}\end{array}$ & $\begin{array}{c}3.04^{* *} \\
{[1.16]}\end{array}$ \\
\hline Post $\times$ High Cov & $\begin{array}{l}0.01 \\
{[0.01]}\end{array}$ & $\begin{array}{l}0.02 \\
{[0.01]}\end{array}$ & $\begin{array}{l}0.04^{* *} \\
{[0.02]}\end{array}$ & $\begin{array}{l}0.02^{*} \\
{[0.01]}\end{array}$ & $\begin{array}{c}0.02 \\
{[0.01]}\end{array}$ & $\begin{array}{c}0.02 \\
{[0.02]}\end{array}$ \\
\hline Equity UGL $\times$ High Cov & $\begin{array}{l}1.01 \\
{[0.64]}\end{array}$ & $\begin{array}{c}1.34 \\
{[0.94]}\end{array}$ & $\begin{array}{l}2.26^{*} \\
{[1.14]}\end{array}$ & $\begin{array}{c}0.69 \\
{[0.60]}\end{array}$ & $\begin{array}{c}1.06 \\
{[0.88]}\end{array}$ & $\begin{array}{l}1.65 \\
{[1.23]}\end{array}$ \\
\hline Equity UGL $\times$ Post $\times$ High Cov & $\begin{array}{l}-0.85 \\
{[0.69]}\end{array}$ & $\begin{array}{l}-1.50^{*} \\
{[0.87]}\end{array}$ & $\begin{array}{c}-3.00^{* * *} \\
{[1.09]}\end{array}$ & $\begin{array}{l}-0.82 \\
{[0.68]}\end{array}$ & $\begin{array}{c}-1.77^{* *} \\
{[0.87]}\end{array}$ & $\begin{array}{c}-2.88^{* *} \\
{[1.16]}\end{array}$ \\
\hline EPS Surprise & $\begin{array}{c}1.00^{* * *} \\
{[0.35]}\end{array}$ & $\begin{array}{c}1.05^{* * *} \\
{[0.37]}\end{array}$ & $\begin{array}{c}0.99^{* * *} \\
{[0.36]}\end{array}$ & $\begin{array}{c}1.04^{* * *} \\
{[0.35]}\end{array}$ & $\begin{array}{c}1.05^{* * *} \\
{[0.38]}\end{array}$ & $\begin{array}{l}1.07^{* *} \\
{[0.42]}\end{array}$ \\
\hline EPS Surprise $\times$ Post & $\begin{array}{l}-0.40 \\
{[0.36]}\end{array}$ & $\begin{array}{l}-0.36 \\
{[0.35]}\end{array}$ & $\begin{array}{l}-0.42 \\
{[0.34]}\end{array}$ & $\begin{array}{l}-0.45 \\
{[0.37]}\end{array}$ & $\begin{array}{l}-0.41 \\
{[0.40]}\end{array}$ & $\begin{array}{l}-0.58 \\
{[0.44]}\end{array}$ \\
\hline Fixed Income UGL & $\begin{array}{l}-0.10 \\
{[0.10]}\end{array}$ & $\begin{array}{l}-0.03 \\
{[0.09]}\end{array}$ & $\begin{array}{c}0.06 \\
{[0.11]}\end{array}$ & $\begin{array}{l}-0.13 \\
{[0.10]}\end{array}$ & $\begin{array}{l}-0.09 \\
{[0.09]}\end{array}$ & $\begin{array}{l}-0.04 \\
{[0.11]}\end{array}$ \\
\hline Fixed Income UGL $\times$ Post & $\begin{array}{l}0.06 \\
{[0.14]}\end{array}$ & $\begin{array}{c}0.01 \\
{[0.13]}\end{array}$ & $\begin{array}{l}-0.04 \\
{[0.18]}\end{array}$ & $\begin{array}{l}0.07 \\
{[0.13]}\end{array}$ & $\begin{array}{c}0.11 \\
{[0.13]}\end{array}$ & $\begin{array}{c}0.14 \\
{[0.17]}\end{array}$ \\
\hline RGL & $\begin{array}{c}0.57 \\
{[0.55]}\end{array}$ & $\begin{array}{l}0.48 \\
{[0.72]}\end{array}$ & $\begin{array}{c}1.20 \\
{[0.89]}\end{array}$ & $\begin{array}{c}0.65 \\
{[0.53]}\end{array}$ & $\begin{array}{c}0.61 \\
{[0.66]}\end{array}$ & $\begin{array}{c}0.84 \\
{[0.79]}\end{array}$ \\
\hline RGL $\times$ Post & $\begin{array}{l}-0.23 \\
{[0.82]}\end{array}$ & $\begin{array}{c}0.32 \\
{[0.97]}\end{array}$ & $\begin{array}{l}-0.39 \\
{[1.22]}\end{array}$ & $\begin{array}{l}-0.13 \\
{[0.68]}\end{array}$ & $\begin{array}{c}0.38 \\
{[0.81]}\end{array}$ & $\begin{array}{c}0.29 \\
{[1.10]}\end{array}$ \\
\hline Log Market Capitalization & $\begin{array}{c}-0.04^{* * * *} \\
{[0.01]}\end{array}$ & $\begin{array}{c}-0.06^{* * *} \\
{[0.01]}\end{array}$ & $\begin{array}{c}-0.09 * * * \\
{[0.01]}\end{array}$ & $\begin{array}{c}-0.04^{* * * *} \\
{[0.01]}\end{array}$ & $\begin{array}{c}-0.06 * * * \\
{[0.01]}\end{array}$ & $\begin{array}{c}-0.07^{* * *} \\
{[0.01]}\end{array}$ \\
\hline Leverage & $\begin{array}{l}-0.01 \\
{[0.01]}\end{array}$ & $\begin{array}{l}-0.00 \\
{[0.01]}\end{array}$ & $\begin{array}{l}-0.00 \\
{[0.01]}\end{array}$ & $\begin{array}{l}-0.01 \\
{[0.01]}\end{array}$ & $\begin{array}{l}-0.00 \\
{[0.01]}\end{array}$ & $\begin{array}{c}0.00 \\
{[0.01]}\end{array}$ \\
\hline Market to Book & $\begin{array}{c}-0.02^{* *} \\
{[0.01]}\end{array}$ & $\begin{array}{c}-0.02^{* * *} \\
{[0.01]}\end{array}$ & $\begin{array}{c}-0.03^{* * *} \\
{[0.01]}\end{array}$ & $\begin{array}{c}-0.01^{* *} \\
{[0.01]}\end{array}$ & $\begin{array}{c}-0.02 * * * \\
{[0.01]}\end{array}$ & $\begin{array}{c}-0.04^{* * *} \\
{[0.01]}\end{array}$ \\
\hline Beta & $\begin{array}{l}0.01 \\
{[0.01]}\end{array}$ & $\begin{array}{c}0.02 \\
{[0.01]}\end{array}$ & $\begin{array}{c}0.00 \\
{[0.02]}\end{array}$ & $\begin{array}{c}0.01 \\
{[0.01]}\end{array}$ & $\begin{array}{c}0.02 \\
{[0.01]}\end{array}$ & $\begin{array}{c}0.01 \\
{[0.02]}\end{array}$ \\
\hline Log Market Capitalization $\times$ Post & $\begin{array}{l}-0.00 \\
{[0.00]}\end{array}$ & $\begin{array}{l}-0.01^{*} \\
{[0.00]}\end{array}$ & $\begin{array}{c}-0.01^{* * * *} \\
{[0.00]}\end{array}$ & $\begin{array}{l}-0.00 \\
{[0.00]}\end{array}$ & $\begin{array}{l}-0.00 \\
{[0.00]}\end{array}$ & $\begin{array}{c}-0.01^{* *} \\
{[0.00]}\end{array}$ \\
\hline Leverage $\times$ Post & $\begin{array}{l}-0.00 \\
{[0.01]}\end{array}$ & $\begin{array}{l}-0.01 \\
{[0.01]}\end{array}$ & $\begin{array}{c}-0.01^{* *} \\
{[0.01]}\end{array}$ & $\begin{array}{l}-0.01 \\
{[0.00]}\end{array}$ & $\begin{array}{l}-0.01 \\
{[0.01]}\end{array}$ & $\begin{array}{l}-0.01 \\
{[0.01]}\end{array}$ \\
\hline Market to Book $\times$ Post & $\begin{array}{c}0.01^{* * *} \\
{[0.00]}\end{array}$ & $\begin{array}{c}0.02^{* * *} \\
{[0.00]}\end{array}$ & $\begin{array}{c}0.02^{* * *} \\
{[0.00]}\end{array}$ & $\begin{array}{l}0.01^{* *} \\
{[0.00]}\end{array}$ & $\begin{array}{c}0.01^{* * *} \\
{[0.00]}\end{array}$ & $\begin{array}{c}0.02^{* * *} * \\
{[0.00]}\end{array}$ \\
\hline Beta $\times$ Post & $\begin{array}{l}-0.02 \\
{[0.01]}\end{array}$ & $\begin{array}{c}0.00 \\
{[0.02]}\end{array}$ & $\begin{array}{c}0.01 \\
{[0.02]}\end{array}$ & $\begin{array}{c}-0.02^{* *} \\
{[0.01]}\end{array}$ & $\begin{array}{l}-0.02 \\
{[0.02]}\end{array}$ & $\begin{array}{l}-0.01 \\
{[0.02]}\end{array}$ \\
\hline $\begin{array}{l}\text { Company FE } \\
\text { Year-Quarter FE }\end{array}$ & $\begin{array}{l}\mathrm{Y} \\
\mathrm{Y}\end{array}$ & $\begin{array}{l}\mathrm{Y} \\
\mathrm{Y}\end{array}$ & $\begin{array}{l}\mathrm{Y} \\
\mathrm{Y}\end{array}$ & $\begin{array}{l}\mathrm{Y} \\
\mathrm{Y}\end{array}$ & $\begin{array}{l}\mathrm{Y} \\
\mathrm{Y}\end{array}$ & $\begin{array}{l}\mathrm{Y} \\
\mathrm{Y}\end{array}$ \\
\hline $\begin{array}{l}\text { Observations } \\
\text { R-squared }\end{array}$ & $\begin{array}{c}1,512 \\
0.19\end{array}$ & $\begin{array}{c}1,512 \\
0.22\end{array}$ & $\begin{array}{c}1,512 \\
0.21\end{array}$ & $\begin{array}{c}1,512 \\
0.19\end{array}$ & $\begin{array}{c}1,512 \\
0.20\end{array}$ & $\begin{array}{c}1,512 \\
0.20\end{array}$ \\
\hline
\end{tabular}


Table A2. Accompanying Regression Results for Figure 9 This table presents panel OLS regression results for variants of equation 5 . The sample consists of public and private insurance subsidiaries, described in Section 5.2 . The dependent variable is equity investment allocation, which is the percentage of the insurer's investment portfolio that is devoted to equity securities multiplied by 100. US Public is an indicator variable that equals 1 if the subsidiary belongs to a parent company that is listed on a US stock exchange. The reference year is 2015. All regressions include subsidiary and year fixed effects. Standard errors are clustered at the subsidiary-level and reported in brackets. Asterisks denote statistical significance at the 1\% (***), 5\% (**), and 10\% (*) level. Coefficients in column 2 are used to construct the plot shown in Figure 9.

\begin{tabular}{lcc}
\hline & $(1)$ & $(2)$ \\
\hline & & \\
US Public $\times \mathbb{1}(2016)$ & -0.12 & -0.14 \\
& {$[0.12]$} & {$[0.13]$} \\
US Public $\times \mathbb{1}(2017)$ & -0.28 & $-0.28^{*}$ \\
& {$[0.17]$} & {$[0.17]$} \\
US Public $\times \mathbb{1}(2018)$ & 0.12 & 0.14 \\
& {$[0.19]$} & {$[0.19]$} \\
US Public $\times \mathbb{1}(2019)$ & $-0.77^{* * *}$ & $-0.76^{* * *}$ \\
& {$[0.22]$} & {$[0.23]$} \\
US Public $\times \mathbb{1}(2020)$ & $-1.16^{* * *}$ & $-1.13^{* * *}$ \\
& {$[0.25]$} & {$[0.25]$} \\
Log Total Assets & & $0.41^{*}$ \\
ROE & & {$[0.24]$} \\
Leverage & & $0.49^{*}$ \\
RBC & & {$[0.29]$} \\
& & $-2.55^{* * *}$ \\
Sample & & {$[0.67]$} \\
Subsidiary FE & & $-0.01^{* * *}$ \\
Year FE & & {$[0.00]$} \\
& & \\
\hline Observations & Y & All \\
R-squared & & Y \\
\hline
\end{tabular}




\section{A.3 Proofs}

\section{Proof of Proposition 2.}

Proof. (1) Note that fixing the regime (either both in the exclusive or in the inclusive regime), inattentive investors have higher residual uncertainty than attentive ones, i.e., $\frac{1}{\operatorname{Var}_{j}^{i}(\theta)}<\frac{1}{\operatorname{Var}_{j}^{a}(\theta)}$. Thus

$$
\frac{\partial \xi}{\partial \kappa}=-\frac{1}{\tau} \xi^{2}\left(\frac{1}{\operatorname{Var}_{j}^{i}(\theta)}-\frac{1}{\operatorname{Var}_{j}^{a}(\theta)}\right)>0 .
$$

(2) Price discount is higher under the inclusive regime, if and only if

$$
\frac{\kappa}{\operatorname{Var}_{\text {inclusive }}^{i}(\theta)}+\frac{1-\kappa}{\operatorname{Var}_{\text {inclusive }}^{a}(\theta)} \leq \frac{\kappa}{\operatorname{Var}_{\text {exclusive }}^{i}(\theta)}+\frac{1-\kappa}{\operatorname{Var}_{\text {exclusive }}^{a}(\theta)}
$$

That is,

$$
\operatorname{Var}_{\text {inclusive }}^{a}(\theta) \geq \operatorname{Var}_{\text {exclusive }}^{a}(\theta)
$$

Equivalently,

$$
\frac{\left(\rho_{1} v_{1}+\rho_{2} v_{2}\right)^{2}}{v_{1}+v_{2}+\sigma_{1}+\sigma_{2}} \leq \frac{\left(\rho_{1} v_{1}\right)^{2}}{v_{1}+\sigma_{1}}
$$

And this gives the condition shown in the proposition.

\section{Proof of Proposition 3.}

Proof. The firm's manager chooses the optimal amount of financial assets by equating the marginal benefit per unit to the marginal cost. The benefit is higher return, while the cost comes from higher residual uncertainty, which demands higher price discounts. The manager's first-order condition for optimal investment level in $\mu_{2}$ equalizes the marginal benefit and cost of investment in financial assets: 


$$
\rho_{2}=\frac{\bar{s}}{\tau} \xi^{2}\left(\frac{\kappa}{\left(\operatorname{Var}_{j}^{i}(\theta)\right)^{2}} \frac{\partial\left(\operatorname{Var}_{j}^{i}(\theta)\right)}{\partial \mu_{2}}\right)+\frac{\bar{s}}{\tau} \xi^{2}\left(\frac{1-\kappa}{\left(\operatorname{Var}_{j}^{a}(\theta)\right)^{2}} \frac{\partial\left(\operatorname{Var}_{j}^{a}(\theta)\right)}{\partial \mu_{2}}\right) .
$$

Under the exclusive regime, higher investment in financial assets leads to higher total uncertainty and the income measure is not informative about it and does not affect the amount of cross learning:

$$
\rho_{2}=\frac{\bar{s}}{\tau} \frac{\partial v_{2}}{\partial \mu_{2}} \rho_{2}^{2}
$$

Under the inclusive regime, higher investment in financial assets leads to higher total uncertainty, but the inclusive regime's summary income measure also changes the amount of uncertainty that gets resolved, and the marginal impact is:

$$
\begin{aligned}
\rho_{2} & =\frac{\bar{s}}{\tau} \frac{\partial v_{2}}{\partial \mu_{2}}\left(\rho_{2}^{2}-\frac{2 \rho_{2}\left(v_{1} \rho_{1}+v_{2} \rho_{2}\right)\left(v_{1}+\sigma_{1}+v_{2}+\sigma_{2}\right)-\left(v_{1} \rho_{1}+v_{2} \rho_{2}\right)^{2}}{\left(v_{1}+\sigma_{1}+v_{2}+\sigma_{2}\right)^{2}}\right) \\
& =\frac{\bar{s}}{\tau} \frac{\partial v_{2}}{\partial \mu_{2}}\left(\rho_{2}^{2}-\frac{\left(v_{1} \rho_{1}+v_{2} \rho_{2}\right)\left(\rho_{2}\left(2 v_{1}+2 \sigma_{1}+v_{2}+2 \sigma_{2}\right)-v_{1} \rho_{1}\right)}{\left(v_{1}+\sigma_{1}+v_{2}+\sigma_{2}\right)^{2}} .\right)
\end{aligned}
$$

Thus, we can see that the optimal $\mu_{2}$ is where the left-hand side and the right-hand side (RHS) intersect. If the RHS is higher under the inclusive regime, then the intersection is smaller under it, i.e., the optimal amount of financial asset is smaller. Let $\mu_{2}^{e x}$ be the optimal amount of financial asset under the exclusive regime and $\mu_{2}^{i n}$ be the optimal amount of financial asset under the inclusive regime. A sufficient condition for $\mu_{2}^{e x}>\mu_{2}^{i n}$ is that $\frac{\left.2 \rho_{2}\left(v_{1} \rho_{1}+v_{2} \rho_{2}\right)\left(v_{1}+\sigma_{1}+v_{2}+\sigma_{2}\right)-\left(v_{1} \rho_{1}+v_{2} \rho_{2}\right)^{2}\right)}{\left(v_{1}+\sigma_{1}+v_{2}+\sigma_{2}\right)^{2}}<0$ for all $\mu_{2}<\mu_{2}^{e x}$. If this condition is true, then the $R H S^{i n}>R H S^{e x}$ for any $\mu_{2}<\mu_{2}^{i n}$, and they both cross the marginal benefit curve of $\rho_{2}$ from below. Thus the optimal amount of financial assets is smaller under the inclusive regime. 